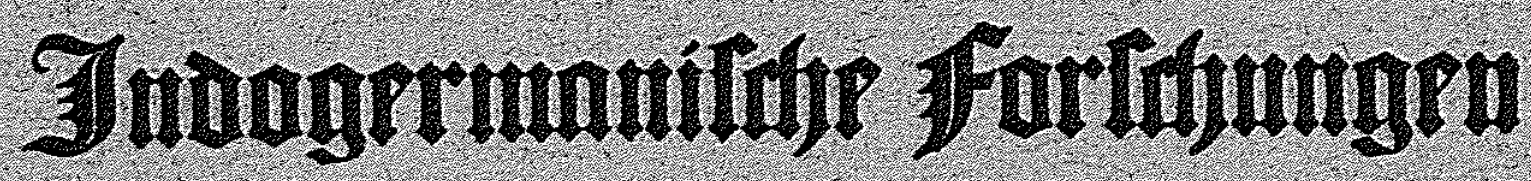

\author{
Zeitschrift für indogermanische \\ Sprach- und Altertumskunde
}

\author{
Herausgegeben ron
}

Karl Brugmann und Wilhelm Streitberg

Mit dem Beiblatt

Anzeiger fuir indogermanische Sprach- und Altertumskunde Herausgegeben von W. Streitberg

XXII. Band: Frstes und zweites Heft

Abgeschlobsen am 8. Novemiber 1907.

Auggegeben am 15. Norember 1907.

Straßburg

Verlag von Karl J. Trübner

1907 


\section{Aktionsart und Zeitstufo der Infinitive in den homerischen Gedichten.}

Nachdem in Griechischen die aus der früheren Sprachentwicklung überkommenen, teils fertigen, teils werdenden Infinitive an die verschiedenen Tempusstämme sich angegliedert hatten, übernahmen sie von den entsprechenden Indikativen die Aktionsart, nicht aber die Z eitstufe. ${ }^{1}$ ) Der Infinitiv des Präsens bezeichnete also die Handlung in der Regel als verlaufend, seltener als punktuell, der Inf. Perf. als abgeschlossen oder den dadurch erreichten Zustand, der Inf. Aor. aber teilte mit dem Ind. Aor. teils die ingressive, teils die effektive Bedeutung. Auf welcher Zeitstufe die Handlung verlaufend, abgeschlossen oder eintretend gedacht werden sollte, ergab der Zusammenhang der Rede.

Die mannigfachen Funktionen, welche von diesen Grundlagen aus die Infinitive nach und nach übernommen haben, liegen in den homerischen Epen im wesentlichen bereits entwickelt vor. Wenn diese aber nach begründeter Annahme den Niederschlag einer Sprachentwicklung von vielleicht sechs Generationen darstellen, so wird sich auf Grund dieses reichen alten Materials die Entwicklung jener Funktionen noch einigermaßen verfolgen lassen. Insbesondere werden die Einflüsse erkeunbar sein, welche die Ausbildung der dem Griechischen eigentümlichen Form der abbängigen Rede auf diese Entwicklung ausgeübt hat. Nach diesen Gesichtspunkten ist im folgenden der homerische Gebrauch der Infinitive in bezug auf Aktionsart und Zeitstufe einer genauen Untersuchung unterzogen.

1. Der Infinitiv Praes. bezeichnet der überwiegenden Bedeutung des Ind. Präs. entsprechend die Handlung als verlaufend und teilt mit ihm die aus dieser Grundanschauung hervorgehenden Gebrauchsweisen. Aus dem Begriff der verlaufenden Handlung,

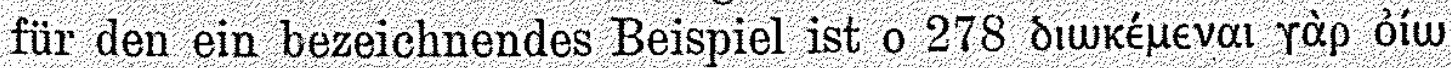
"daß sie auf der Verfolgung begriffen sind", erklärt sich zunächst der nur seltene, sogenannte Gebrauch de conatu. Mutzbauer Die Grundlagen der griech. Tempuslehre, S. 45 bemerkt mit Bezug auf das Imperf. mit Recht, daß in der Form nichts

1) Vgl. Delbrück Die Grundlagen der griech. Syntax S. 121 ff. und Vergl. Syntax II S. $451 \mathrm{ff}$, Gapelle im Philologus 37 S. 114. 


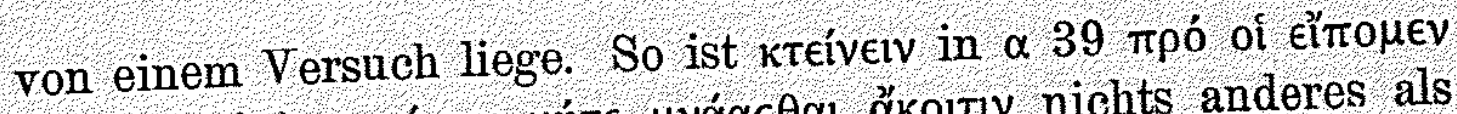

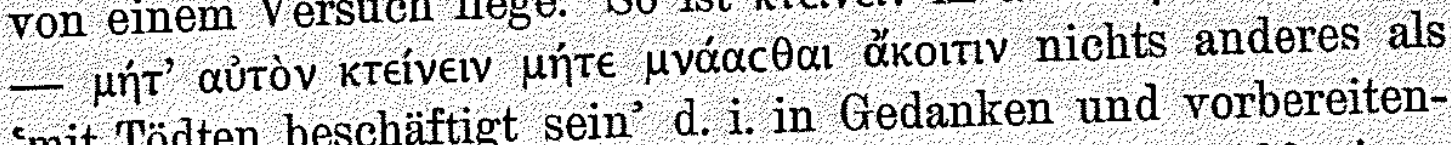
'mit Tödten beschäftigt sein' d. i. in Gedanken und vorbereitenden Handlungen den Mord betreiben, kataktéveiv $\pi 400$ einen Mordanschlag machen, rgl. 432, ìáckec $\theta \alpha$ A A 386 die Versöhnung betreiben, vgl. 472.1) Die Handlung ist ferner in ihrem Verlauf gedacht, wenn es sich um die Fortsetzung oder Beendigung einer bisher geübten Tätigkeit handelt: so in der Konstruktion

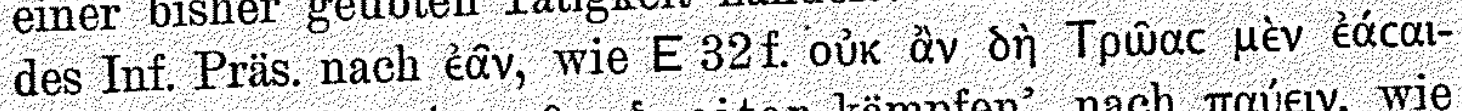
$\mu \in v$ kai 'Axaıoùc $\mu a ́ p v a c \theta \alpha i$ 'weiter kämpfen', nach raúeıv, wie

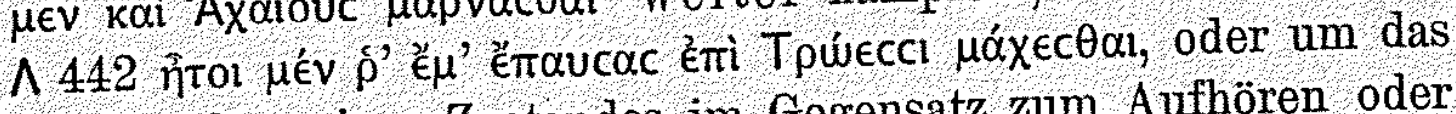
Fortbestehen eines Zustandes im Gegensatz zum A ufhören oder

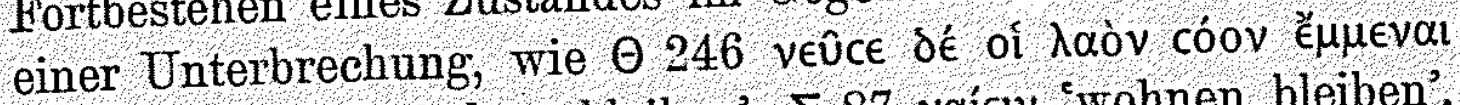

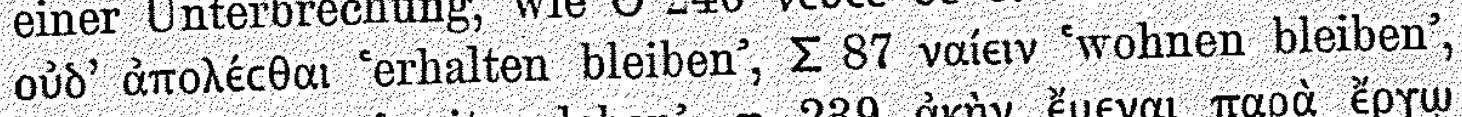

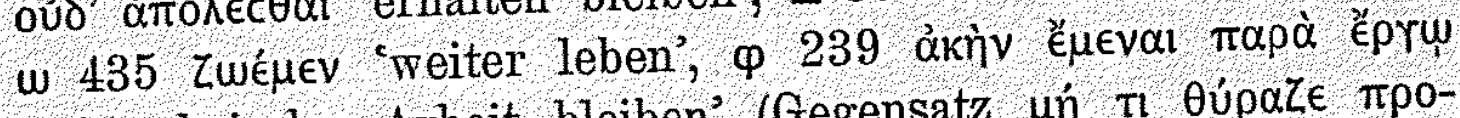
'ruhig bei der Arbeit bleiben' (Gegensatz $\mu$ ' $\pi$ oúpale $\pi \rho 0-$

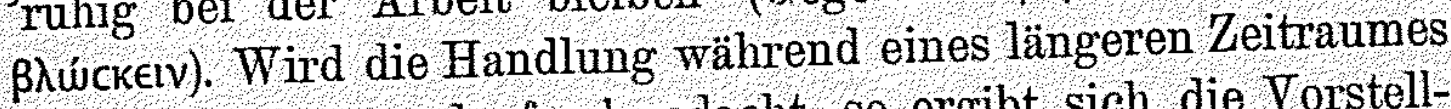
ununterbrochen verlaufend gedacht, so ergibt sich die Vorstell-

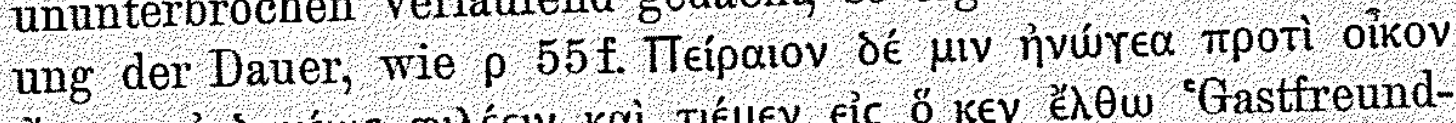

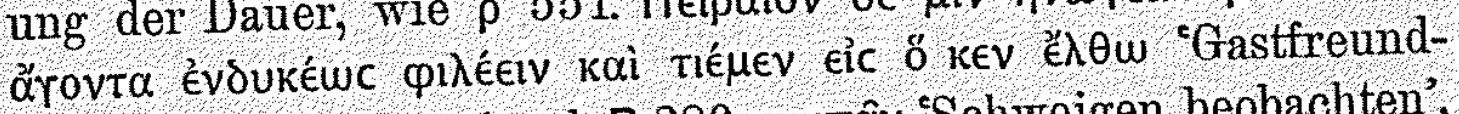
schaft und Ehre erweisen', B 280 clwrâv 'Schweigen beobachten',

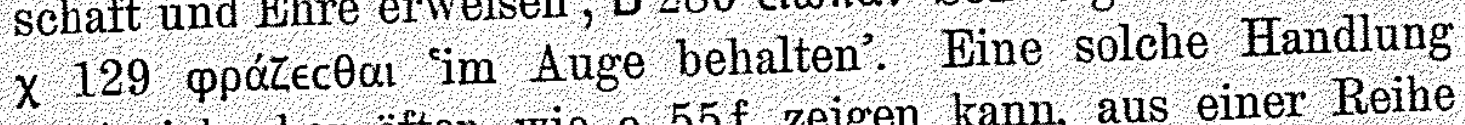
setzt sich aber öfter, wie p $55 \mathrm{f}$. zeigen kann, aus einer Reihe einzelner gleicher Akte zusammen, daher der Inf. Präs, wie der Ind, auch zur Bezeichnung einer wiederholten Handlung verwendet wird. So von gewohnheitsmäBigem Tun $\curlyvee 48$ e $\pi \epsilon i$ kai

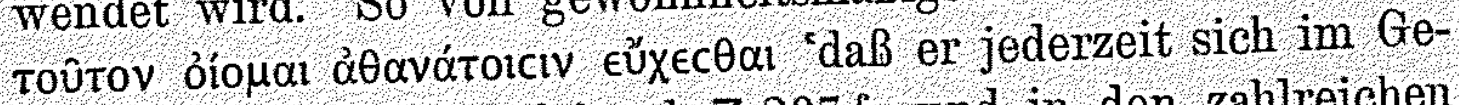
bet an die Götter wende' $\mathrm{vgl}$. Z 207f, und in den zahlreichen Beispielen, in denen im Nebensatz ein wiederholter Fall gesetzt

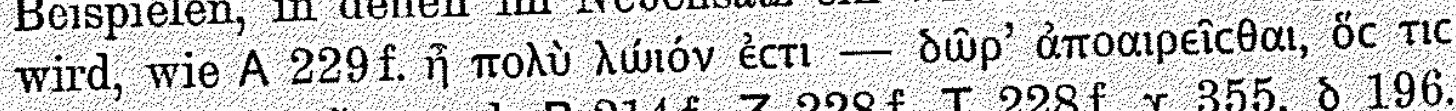

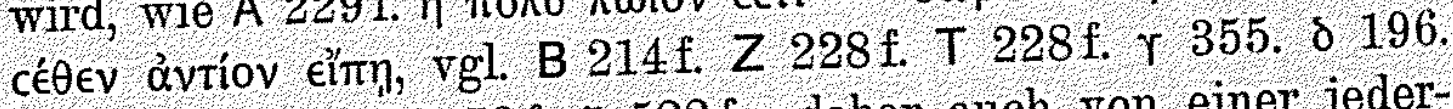
e 119f. 045 . k 22. $73 \mathrm{f}$ \& $522 \mathrm{f}$; daher auch von einer jeder-

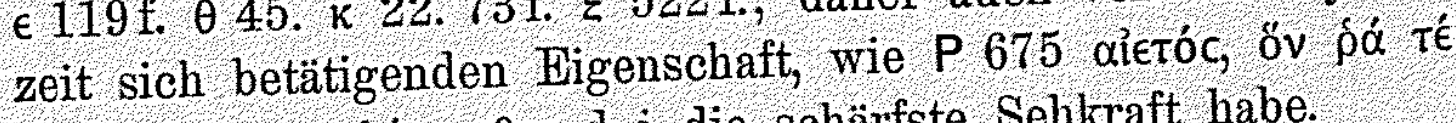

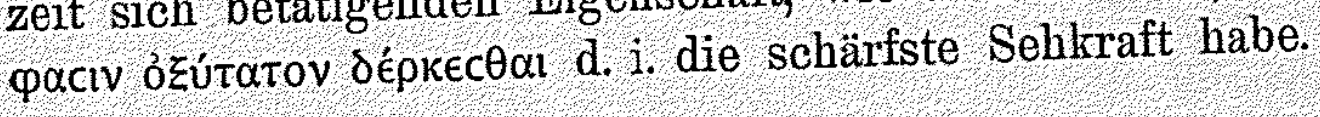

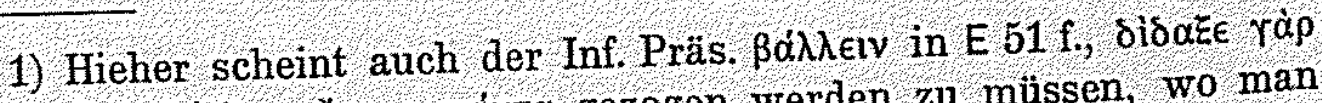

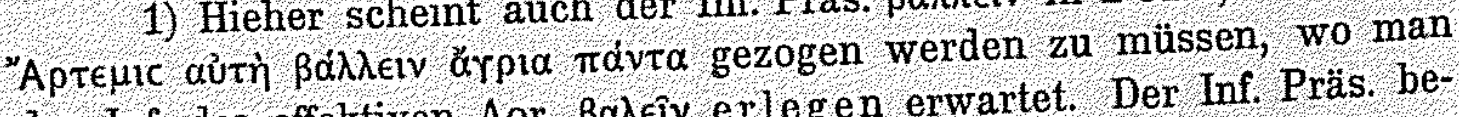
den Inf des effektiven Aor. Baגeiv erleg en erwartet. Der Inf. Präs. besagt eigentlich 'schießen auf allerlei Wild', die Jagd auf jegliche Art von

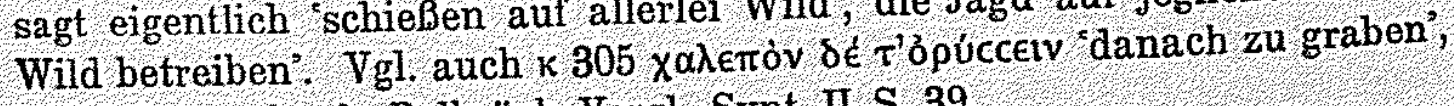
nicht 'ausgraben': Delbrück Vergl. Synt. II S. 39. 
Wenige Präsensstämme bezeichnen eine punktuelle Aktion in dem von Delbrück Vergl. Synt. 2, 14 festgestellten Sinne, daß die Handlung mit ihrem Eintritt zugleich vollendet ist, oder auch verschiedene Alktionsarten. Zu den ersteren gehört vor

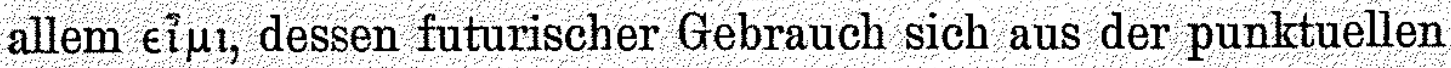
Aktion erklärt. Futurisch wird dies Verbum nach Delbrück $2,69 \mathrm{f}$. im Ind. Präs. bei Homer besonders in der 1. und 2. Person gebraucht, zugleich aber verlaufend gedacht K 325 ró $\varphi \rho \alpha$ rò $\rho$ éc

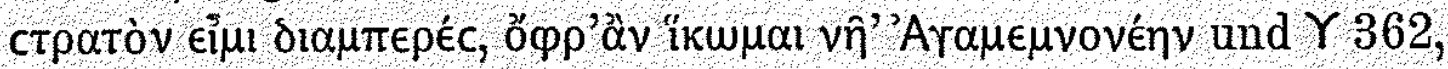
während die 3 . Person meist präsentisch von verlaufender Alktion gebraucht wird. Der Infinitiv zeigt nun folgende Aktionsarten. In abhängiger Rede überwiegt die punktuell-futurische

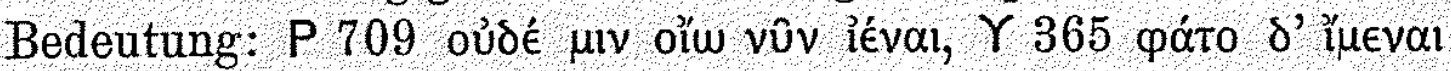

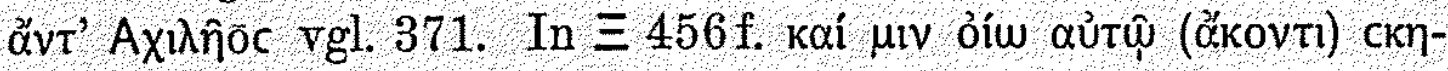

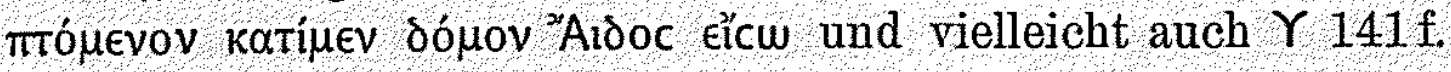

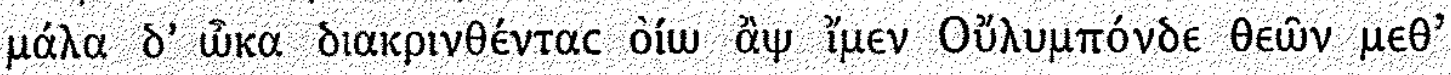

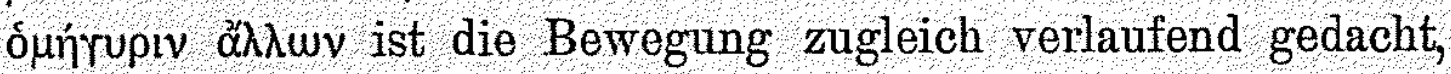
wie im Ind. K 325 und $\Upsilon 362$. Gegenwärtig verlaufend aber

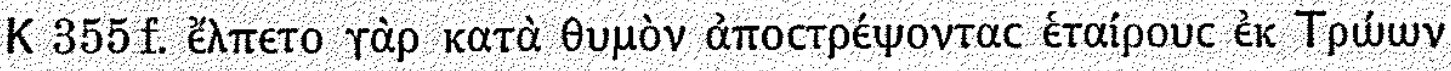
leval, wo Dolon die ihn verfolgenden Odysseus und Diomedes hat kommen hören, und auch N 99 ff. î $\mu \epsilon\} \alpha \theta \alpha u \mu \alpha$ тód' ó $\varphi \theta \alpha \lambda$ -

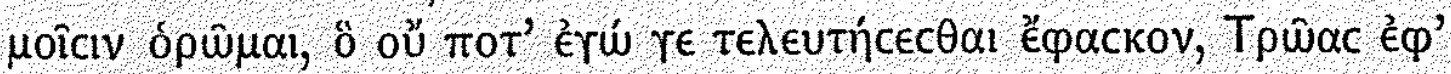

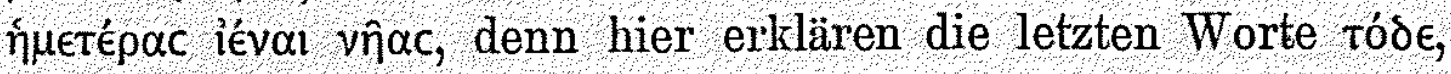
zwar eine Tatsache, die aber unter Einwirkung des vorhergehenden Relativsatzes als Vorstellung gefaßt ist: daß die Troer im Anrücken gegen unsere Schiffe begriffen sind. Punktuell ist die Aktionsart des Inf. im imperativischen Gebrauch, sowohl im selbständigen: $\Pi 87.839 . \Phi$ 297. 乙 298. $\theta$ 12. к 405. 512. ค 600, als im abhängigen: $\Lambda$ 686. $\alpha 374$, auch in Abhängigkeit ron Verben des Antreibens, Befehlens, Wollens, Verlangens, nur in

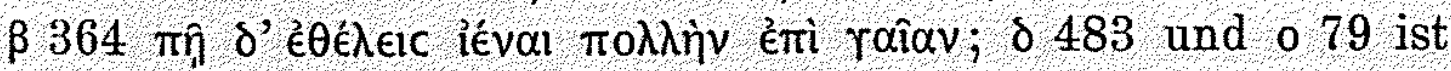
die Bewegung verlaufend gedacht. In der Verbindung $\beta \hat{n} \delta^{\prime}$ í́val

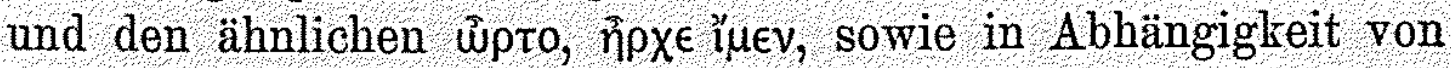

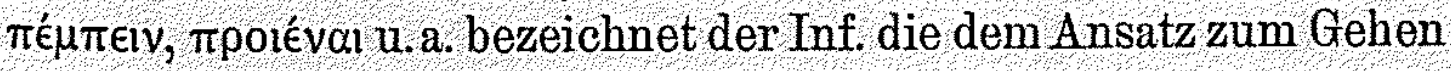

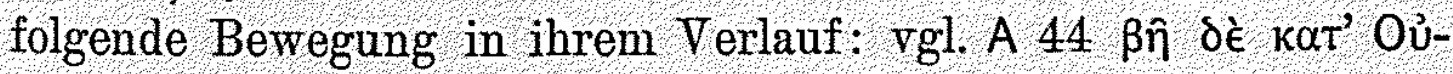

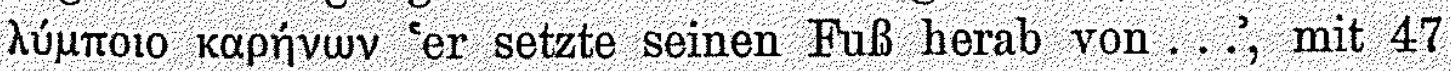
ó $\delta$ ' h'le vukti éolkẃc 'er schritt dahin'.

Der Ind. von $v^{\prime} \circ \mu \alpha \imath$ hat überwiegend futurische Bedeutung, präsentische nur in der Odyssee: $\mu$ 188. k 192 und viel-

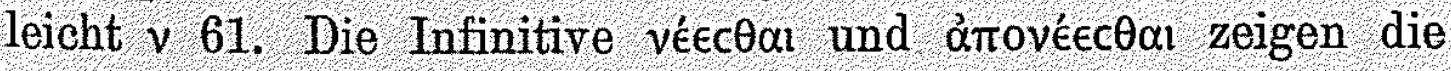


punktuell-futurische Bedeutung in abhängiger Rede: nach úrte-

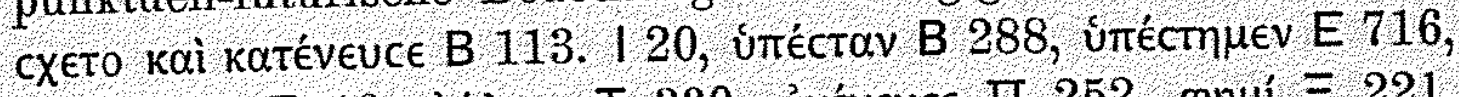

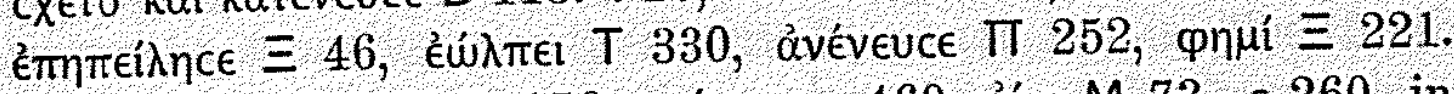

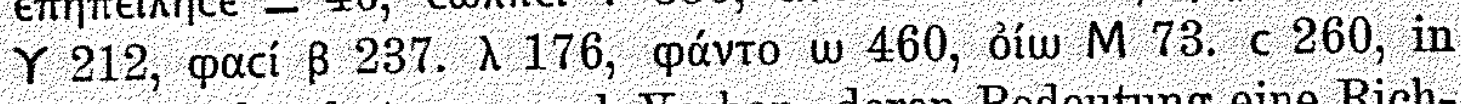
der llias also fast nur nach Verben, deren Bedeutung eine Richtung auf die Zukunft enthält, in der Odyssee nur nach $\varphi \eta \mu \mathrm{i}$ und ólw. Ferner ist die Bedeutung des Inf. punktuell im imperativischen Gebrauch, selbständig $\pi 132$, abhängig $\pi 350$, und auch sonst überall in Abhängigkeit von Verben; nur wird in den nach dem Muster von $\beta \hat{\eta} \delta$ ' léval gebildeten Verbindungen é $\beta \alpha v$ véec $\theta \alpha l$

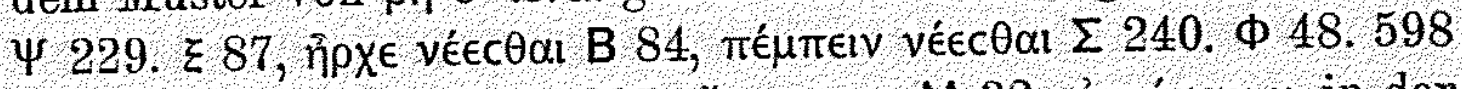

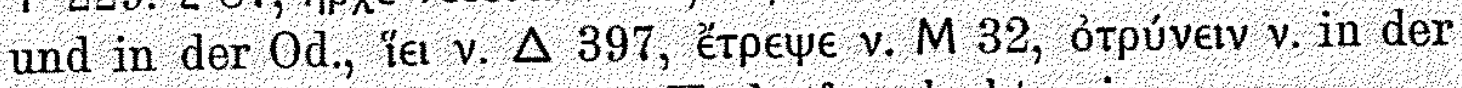
Od. die Bewegung in ihrem Verlauf gedacht sein.

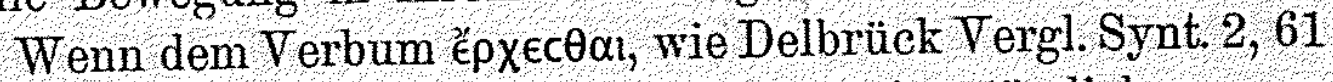
annimmt, ursprünglich terminative Aktion eigentümlich war, so daß es, je nachdem der Ausgangspunkt oder der Endpunkt der Bewegung in das Auge gefaßt wurde, entweder 'weggehn' oder 'kommen' bezeichnete, so hat es doch bei Homer im Ind, wie in andern Formen des Präs, daneben nicht selten auch kursive Altion. Ich hebe nur einige Beispiele heraus: épxoua $\Lambda 839$. N 256. 三 301 in der Bedeutung ich bin auf dem Wege', vgl.

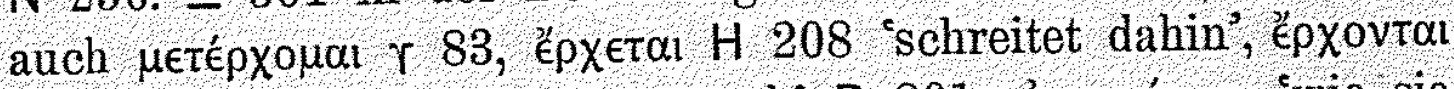

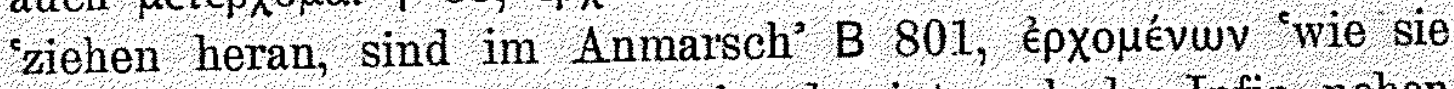
dahin zogen' $\Gamma 14$. Dementsprechend zeigt auch der Infin. neben der terminativen, zum teil auch kursive Aktion; erstere $\Gamma 392 \mathrm{ff}$.

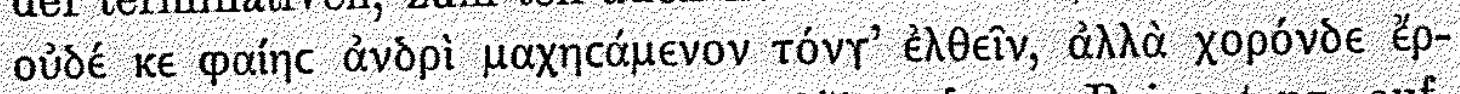

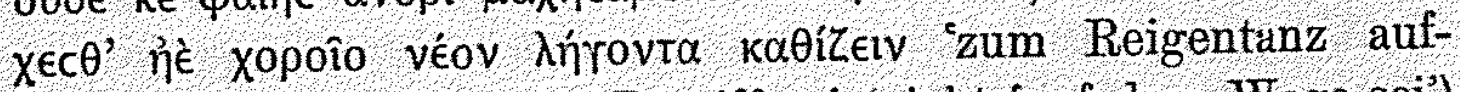
breche oder zu gehen im Begriff sei (nicht 'auf dem Wege sei) im Gegensatz zu e $\lambda \theta \in i$ v 'zurückgekommen sei', vgl. $Z$, 65 , so auch

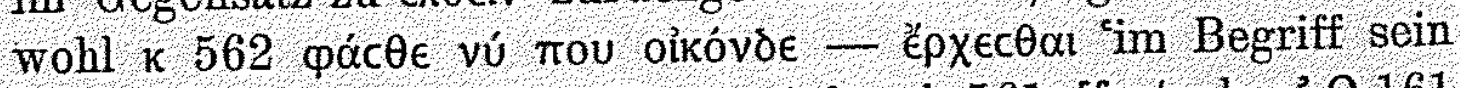
zu gehen', nicht 'auf dem Wege sein', rgl. 561, 'fortgehen' O 161

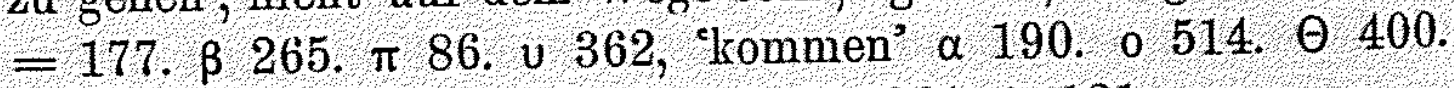
Dagegen sicher kursive Aktion 2 40, 261, $\lambda 121$.

Die vermutlich aus Perfekten entstandenen Präsentia ikw und olıouri, die im Ind. neben der präsentischen auch Perfektbedeutung haben, zeigen die letztere auch im Infin. : v 325 oủ rò $\rho$ ów ikelv (so Bekker und Neuere, handschriftlich nur

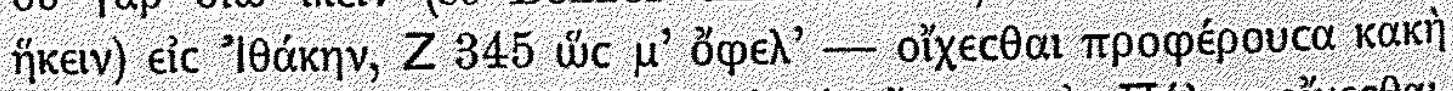

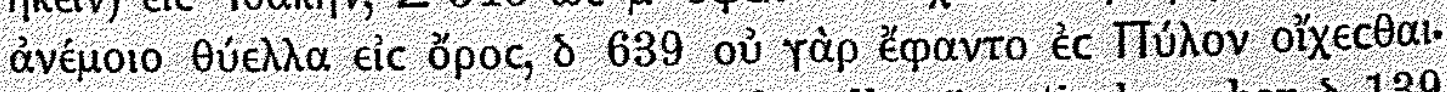
- ikóvw zeigt im Infin. o 29 punktuell-präsentische, aber $\delta 139$ 


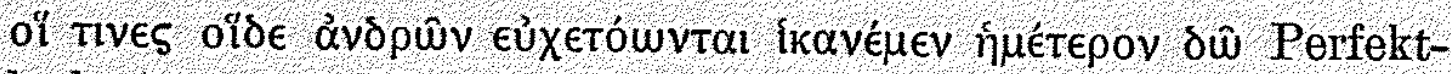
bedeutung. - Die scheinbar perfektische Bedeutung der Präs. ákoúw $(\Omega$ 543. o 403) 'ich habe gebört' und vikáw ich bin Sieger' (B 370. r 121) wiederholt sich in den Infin. ákové $\mu \in v$ $\equiv 125$ und $\delta 94, v_{i \kappa \alpha \alpha \nu} \lambda 548$.

Auf welcher Zeitstufe die Handlung des Infin. Präs. in den nachgewiesenen Aktionsarten vor sich gehend gedacht werden sollte, ergab der Zusammenhang der Rede. So lange nun der Gebrauch der Infinitive im wesentlichen auf die finale und konsekutive Bedeutung beschränkt war, fiel die Handlung des Infin. seiner ursprünglich dativischen Natur entsprechend in die Zukunft, die in Beispielen, wie $\Psi 618$ เñ vôv, kai coi toûto,

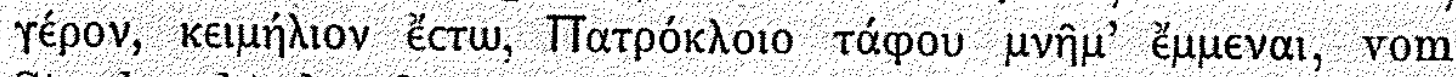
Standpunkt der Gegenwart des Redenden aus bestimmt wurde,

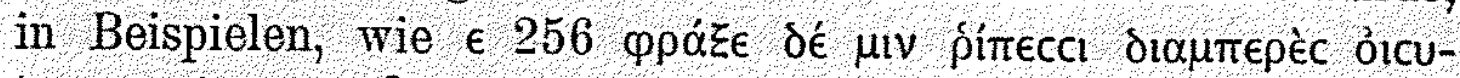

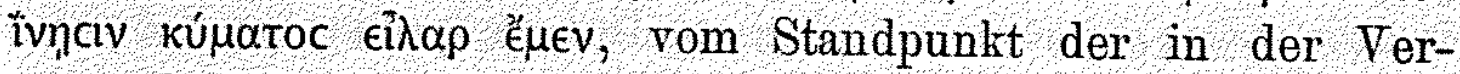
gangenheit handelnd eingeführten Person aus. Erst durch die Ausbildung der abhängigen Rede erweiterte sich der Gebrauch des Infin. Präs. dahin, daß er auch eine in der Gegenwart verlaufende Handlung oder einen in der Gegenwart dauernden Zustand bezeichnen konnte, ebensowohl rom Standpunkt des

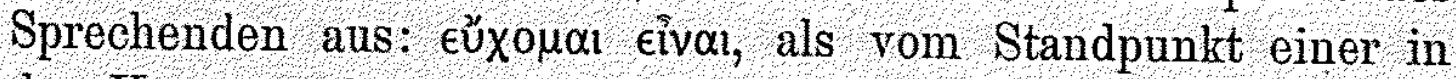
der Vergangenheit sprechend eingeführten Person aus: EủX $\in$ to Eival. Die letzte Stufe der Entwicklung war die, daß der Infin. Präs. auch verwendet wurde, um eine in der Vergangenheit verlaufende Handlung (Zustand) zu bezeichnen, ohne daß die Zeitstufe der Vergangenheit aus dem Verbum des regierenden Satzes entnommen werden konnte, wie $\chi 321$ ei $\mu \in \hat{V}$ ờ $\mu \in \tau \alpha$ toícl Өuockóoc EủXeal Eîval, wo die Bedeutung 'gewesen zu sein' nur aus den vorhergehenden Worten des Leodes 313 - 319 verständlich ist. Dieser sog. imperfektische Gebrauch des Infin. Präs. findet sich überhaupt nur in 10 Beispielen (Il. 3, Od. 7) und steht noch in den Anfängen der Entwicklung. Er wird sich zunächst auf den Infin. eival bei Angabe von Eigenschaften und Zuständen beschränkt haben : die drei Beispiele der llias in $\triangle E \Omega$ enthalten nur diesen Infinitiv und von den 7 Beispielen der Odyssee 5 denselben, und nur 2 solche Infinitive, welche eine in der Vergangenheit vollzogene Handlung bezeichnen. Ton selbst ergab sich die Beziehung des Inf. Präs. auf die Ver-

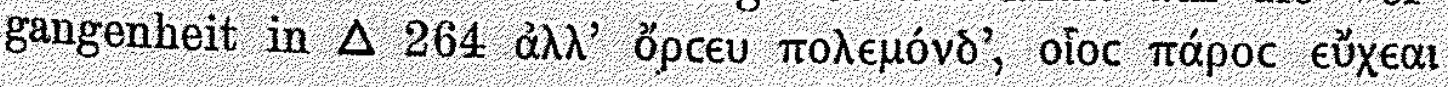




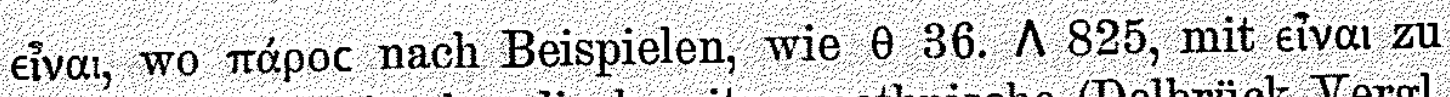
verbinden ist: hier lag die bereits proethnische (Delbrück Vergl.

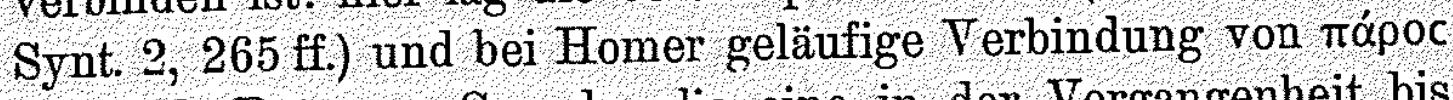
mit Ind. Präs. zu Grunde, die eine in der Vergangenheit bis zur Gegenwart betätigte Eigenschaft bezeichnet. Nötig war der

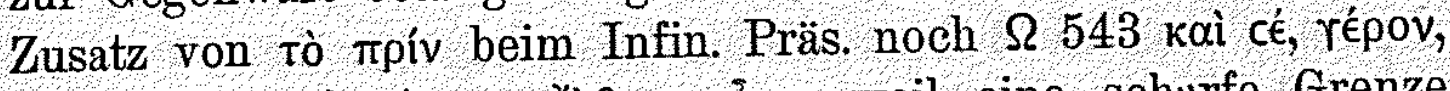

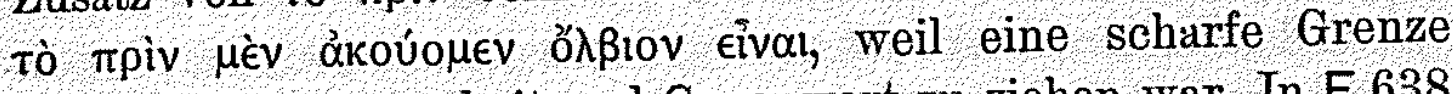
zwischen Vergangenheit und Gegenwart zu ziehen war. In E 638

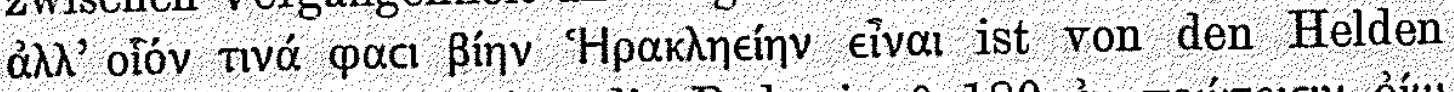
einer frühern Generation die Rede, in $\theta 180$ év Tpútoıclv ỏíw

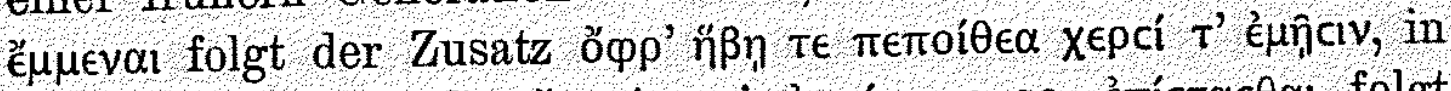

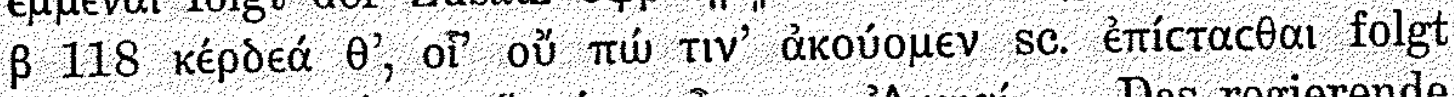

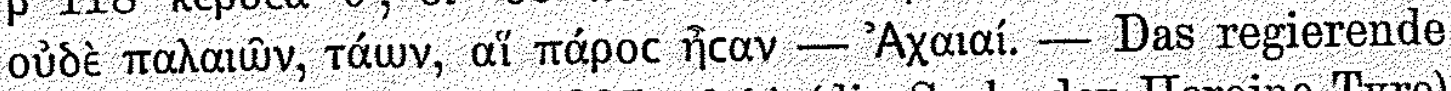
Verbum steht im Prät. $\lambda 237$ фñ dé (die Seele der Heroine Tyro)

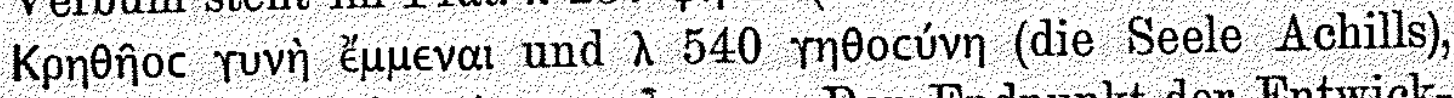

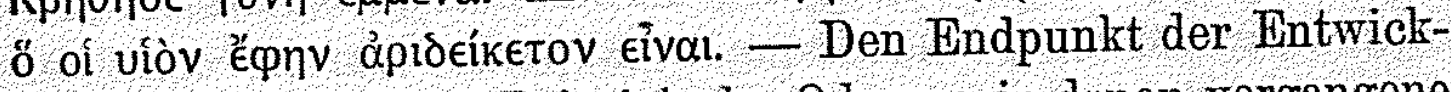
lung bezeichnen die 2 Beispiele der Odyssee, in denen vergangene Handlungen durch den Infin. Präs. bezeichnet werden: $\theta 516$

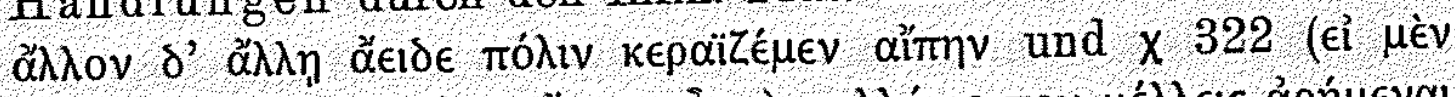

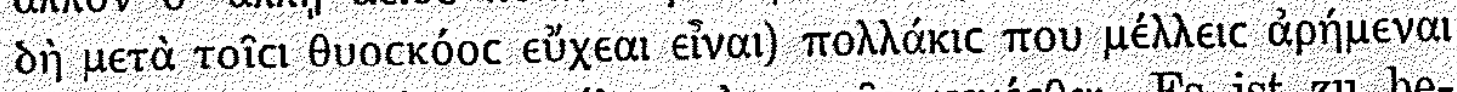

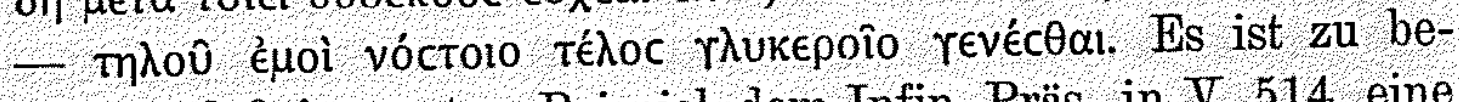
achten, daß im ersten Beispiel dem Infin. Präs. in V. 514 eine

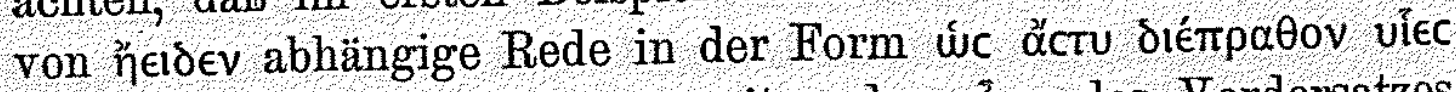
${ }^{2}$ Axalww vorhergeht und im zweiten das eival des Vordersatzes schon eine der Vergangenheit angehörende Stellung des Angeredeten bezeichnet.

2. Verhältnißmäßig gering ist der Gebrauch der abhängigen Infinitive Perf, von denen sich nur 102 Beispiele finden (11. 67, Od. 35). Am häufigsten sind vertreten die Inf. Eccóa $\mu \in v$

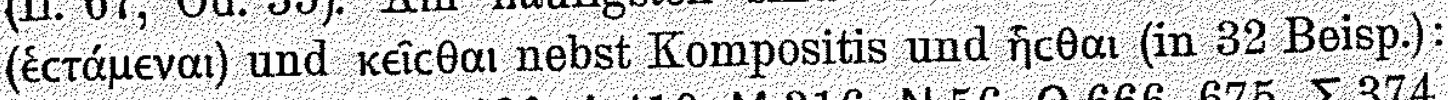

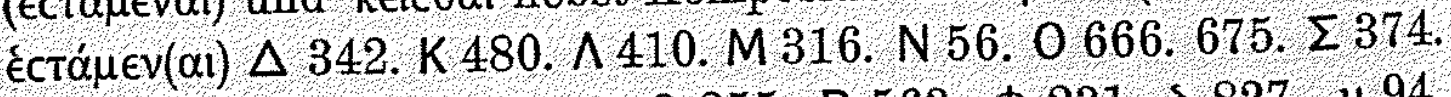

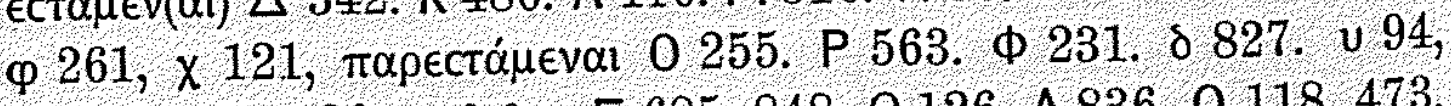

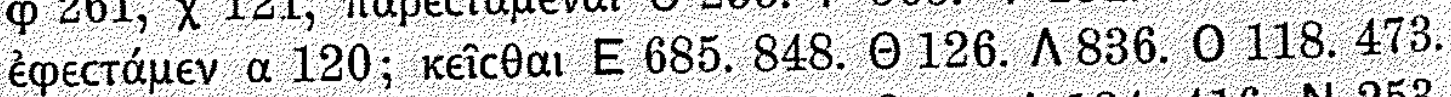

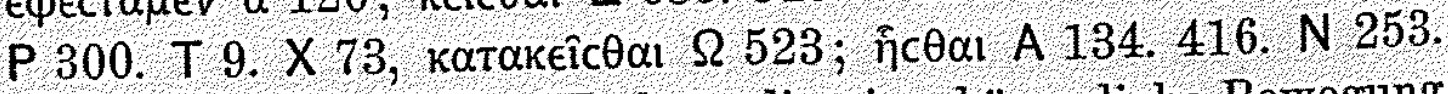
280. ๆ 160, т 120. Von Verben, die eine körperliche Bewegung

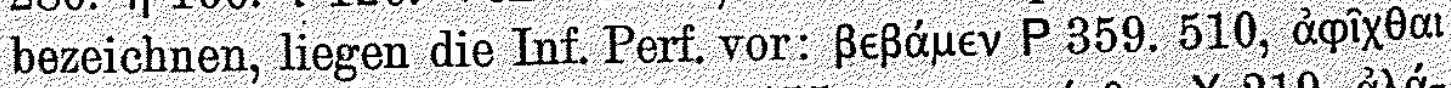

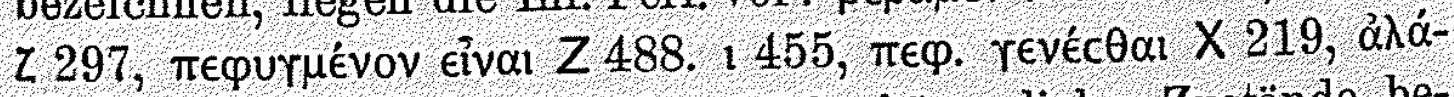

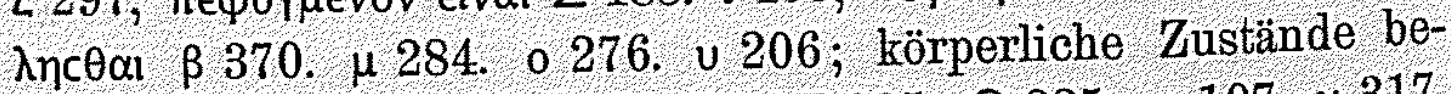

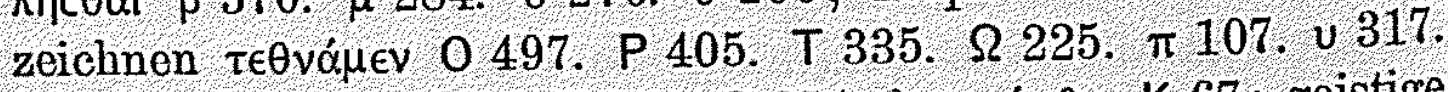

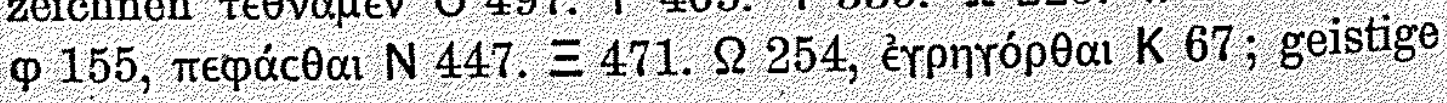




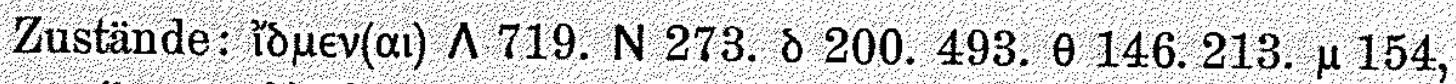

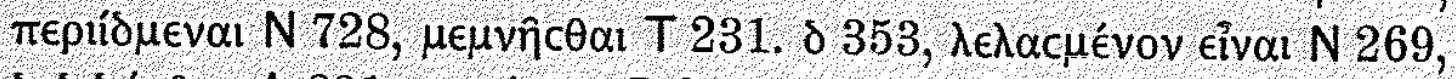

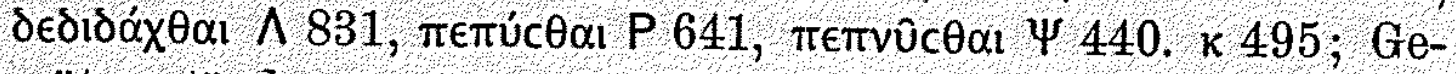

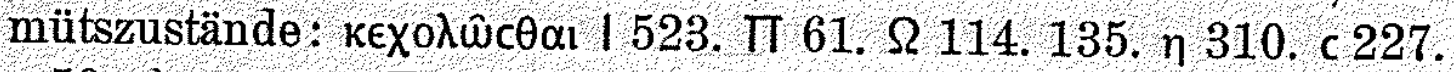

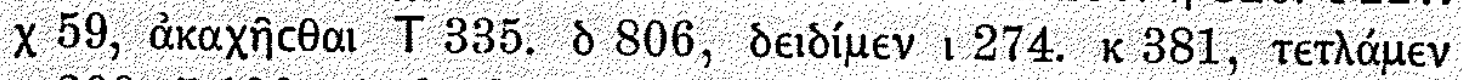

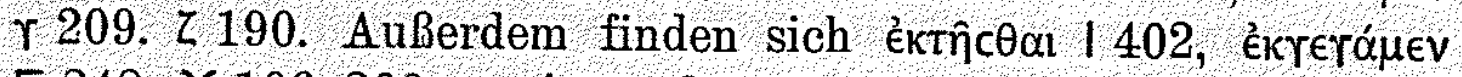

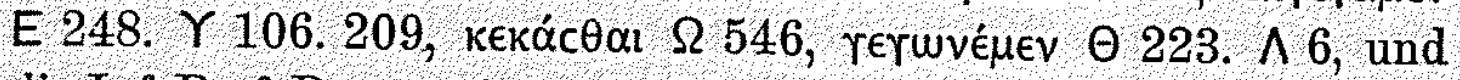

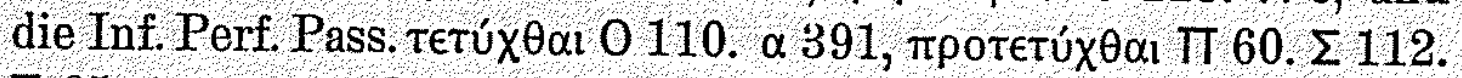

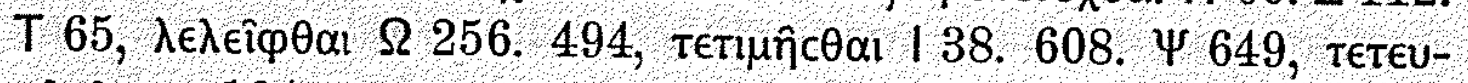

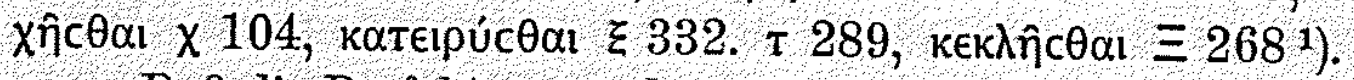

Daß die Perfekta, von denen Infinitive vorliegen, den durch eine vorhergehende Handlung erreichten Zustand bezeichnen und nicht einem Teil derselben intensive Bedeutung beizulegen ist, hat Delbrück Vergl. Synt. I, $177 \mathrm{ff}$. wahrscheinlich gemacht.

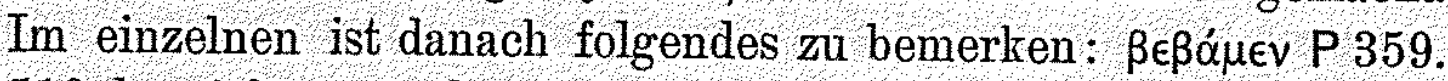
510 bezeichnet weder 'schützend schreiten um', noch einfach

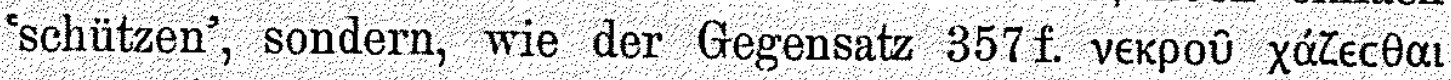

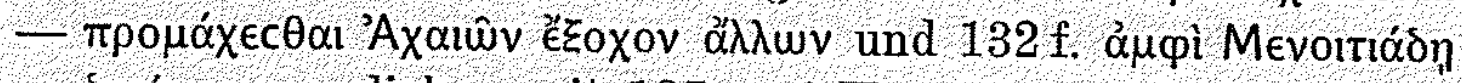

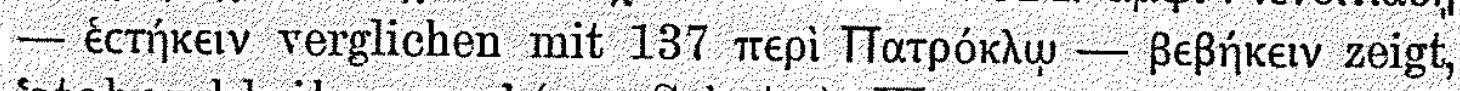
'stehen bleiben vor' (zum Schutze). Wenn man ferner re $\theta$ vá $\mu \in v$ P 405. $\Omega$ 225. 0497 intensive Bedeutung beilegt, so zeigt doch

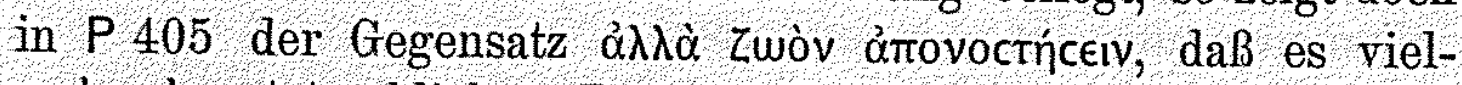
mehr den tatsächlichen Zustand des Patroklos bezeichnet: er-

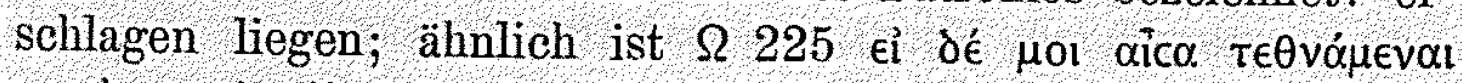
rapa vnuaiv 'Axalŵv tot liegen bleiben bei den Schiffen der Achaeer ${ }^{2}$ statt lebend aus dem Schiffslager zurückzukehren, und

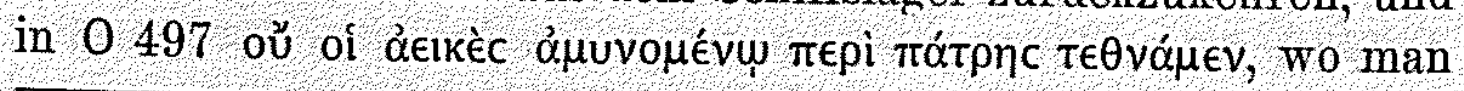

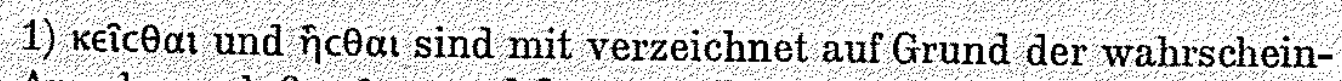
lichen Annahme, daß keîual und ñual aus Perfekten umgebildete Präsentia sind, vergl. Delbrück Vergl. Synt. II, 68, 187. Dagegen sind die Formen $\pi \in \pi \alpha \lambda \alpha c \theta \alpha l, 331$ und $\delta \in \delta \alpha \alpha c \theta a l$ $\pi 316$ als zweifelhaft ausgeschlossen. In beiden Stellen ist es schwer, die erforderliche Bedeutung aus einem Perfekt des erreichten Zustandes abzuleiten, auch erwartet man eher Infinitive des Aor. Für $\delta \in \delta \alpha \alpha c \theta \alpha$ l hat Wackernagel in Bezzenbergers Beitr. IV S. 310 die Möglichkeit eines Inf. Aor. erwiesen und an Stelle von $\pi \in \pi \alpha$ -

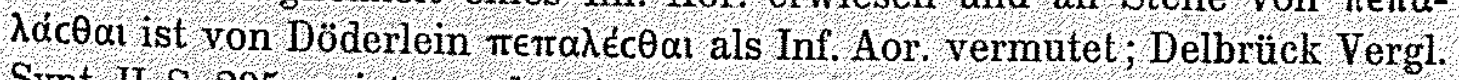
Synt. II S. 205 neigt zu der Annahme, daß $\pi \in \pi \alpha \lambda \alpha c \theta \alpha$ Inf. Aor. sei. Hinsichtlich der imperativisch gebrauchten Inf. Perf. ist zu bemerken, daß

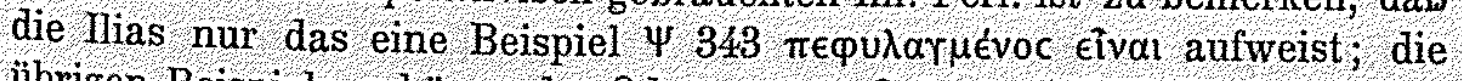

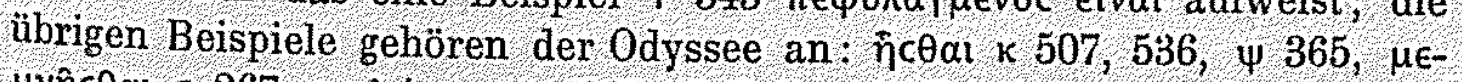

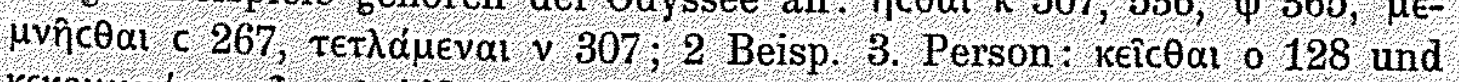

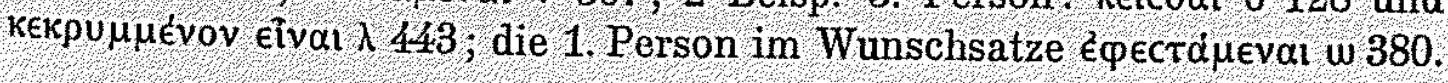


den Inf. Aor. erwarten könnte, ist der Inf. Perf. bedingt durch тє日vátw 496, dieses Perf. bezeichnet aber, wie der Vordersatz

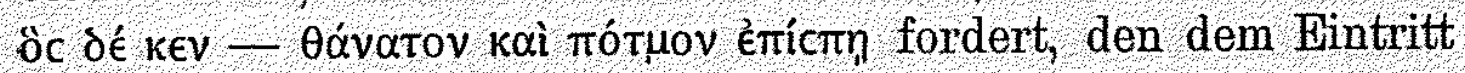
des Todes folgenden Zustand, wie auch der Inf. Perf. $\pi 106$

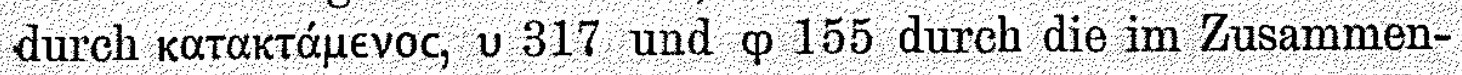
hange vorausgesetzte Tötung bedingt ist. V gl, auch T $334 \mathrm{f}$. Wie ferner $\mathrm{T} \in \theta$ vó $\mu \in \nu$ P 405 den Zustand bezeichnet, in dem sich

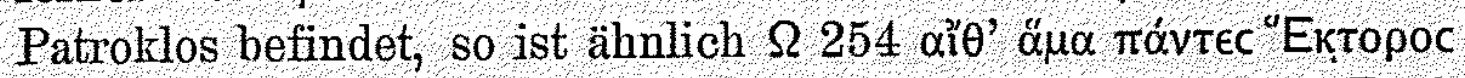

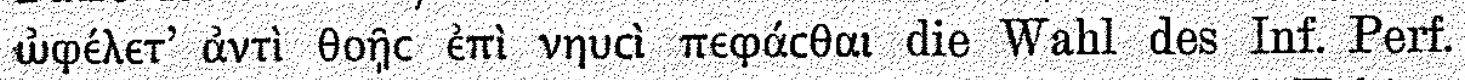
'erschlagen liegen' bedingt durch die Beziehung auf Hektor, der in Schiffslager tot liegt, wie in $\equiv 471$ i $\rho^{\prime}$ oúx oưtoc ơvǹ $\rho$

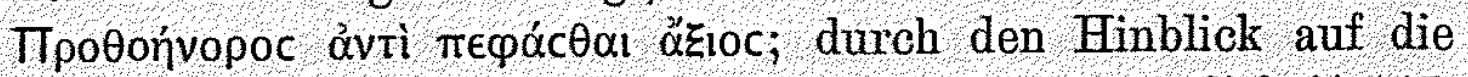
an Boden liegende Leiche des eben Gefallenen, ähnlich N 447.

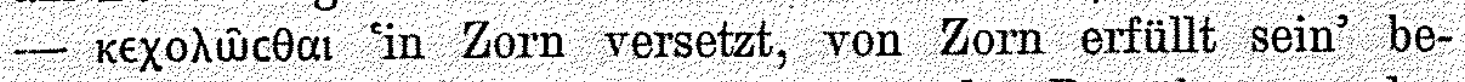
zeichnet 1523 und x 59 im Gegensatz zu den Bemühungen, den

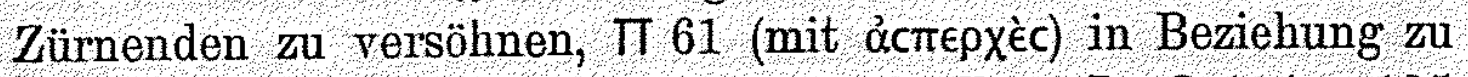

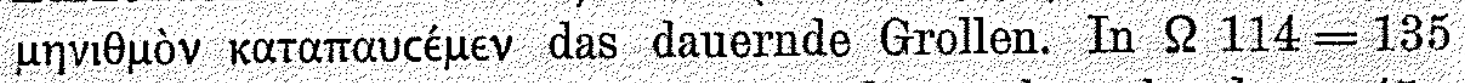
scheint $\kappa \in \chi \circ \lambda \omega \omega c \theta a l$ eine Steigerung des vorhergehenden ckúlte-

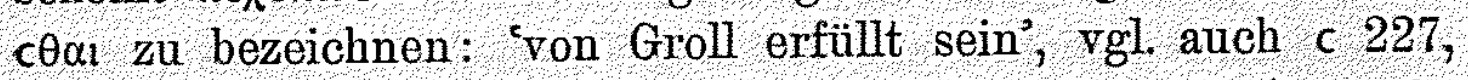

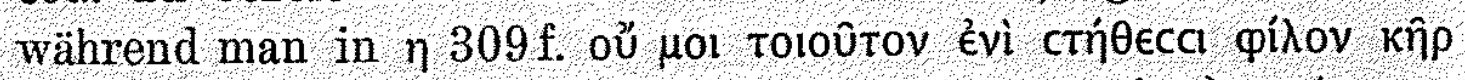

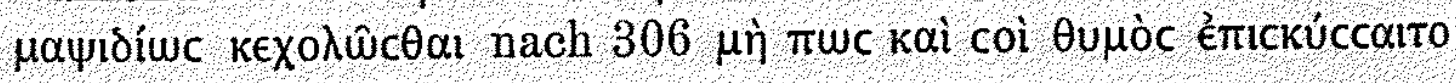
ioovti eher den Inf. Aor. erwartet.

Recht augenfällig ist der Inf. Perf. als Ausdruck des durch eine vorhergehende Handlung bewirkten Zustandes in den Ver-

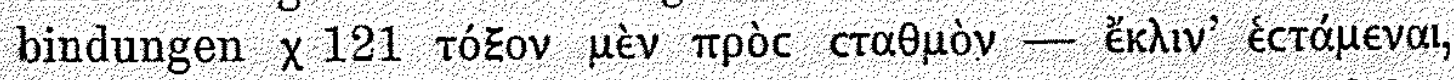

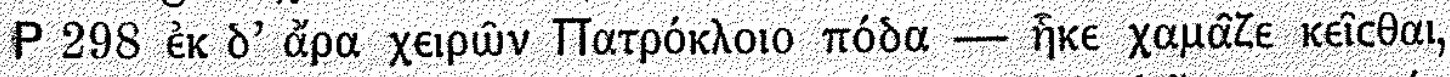

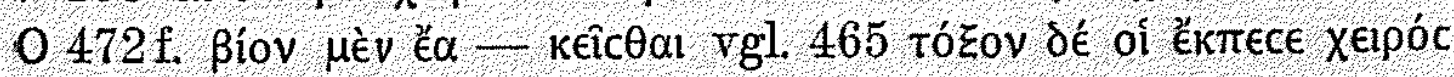
und in der öfter in bezug auf einen eben Gefallenen gebrauchten

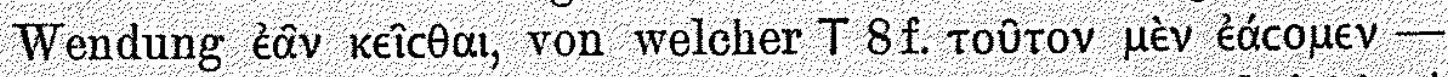

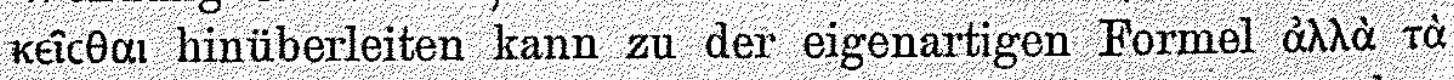

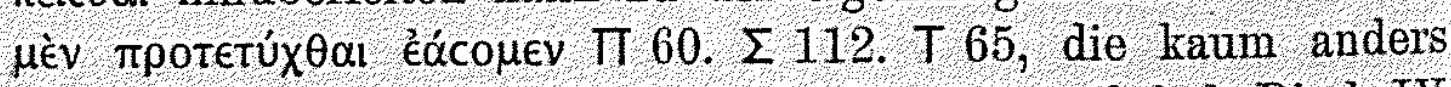
verstanden werden kann, als nach den Alten (Schol. Dind. IV S. 206 zu T 65): doch wir wollen das vorhergeschehen sein lassen d. i. als ein für allemal abgetan auf sich beruhen lassen,

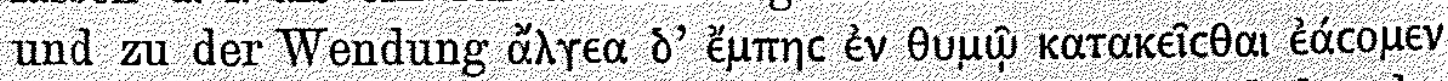
$\Omega 522 \mathrm{f}$. Durch kai verbunden sind die Handlung und der da-

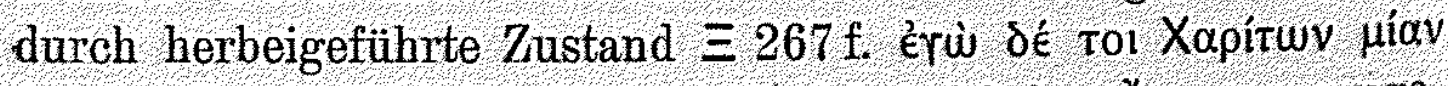

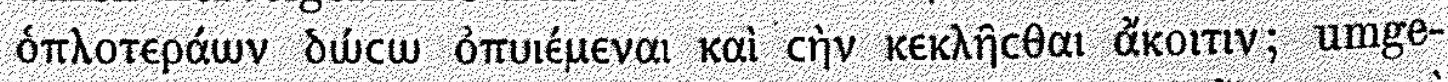
kehrt ist das dauernde Ergebnis vorangestellt $\delta 493$ ibueval kai

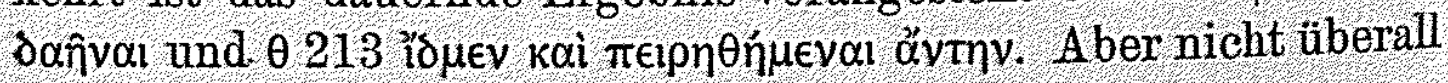


ist die Wahl des Inf. Perf. statt des Inf. Aor. ohne weiteres verständlich. Zu dem schon erwähnten Beispiel $\eta 309 \mathrm{f}$. Kommen

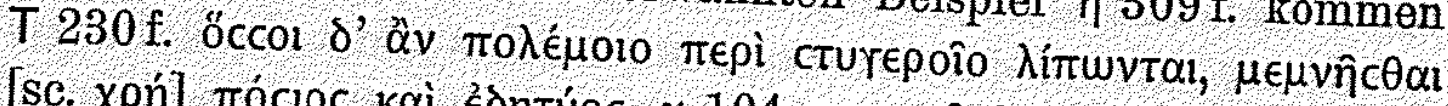

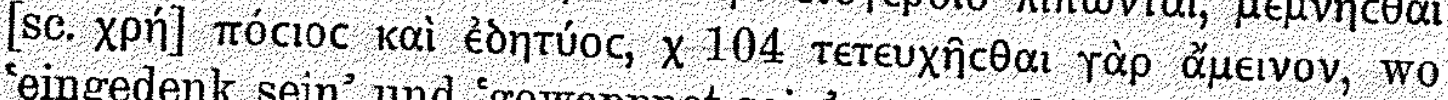
'eingedenk sein' und 'gewappnet sein' nur nachdrucksvoller statt

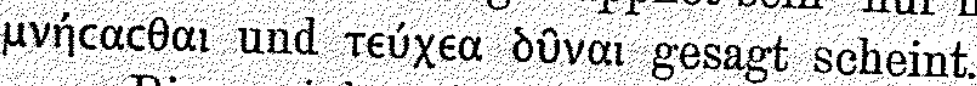

Die periphrastische Verbindung des Partiz. Perf. mit eival prägt den Begriff des Zuständlichen noch kräftiger aus, als der

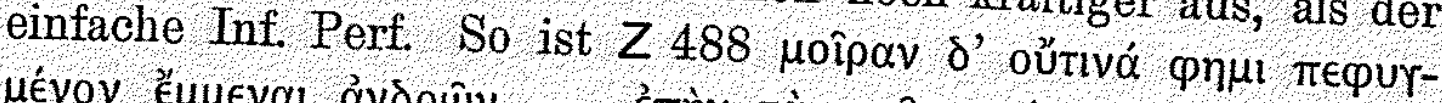

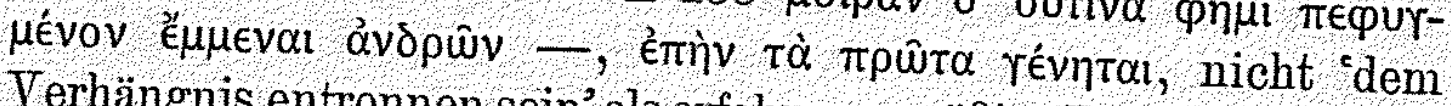
Verhängnis entronnen sein' als erfahrungsmäßigeTatsache, sondern in Sicherheit sein vor dem Verhängnis', l 455 ov oú $\pi u ́$ $\varphi \eta \mu$

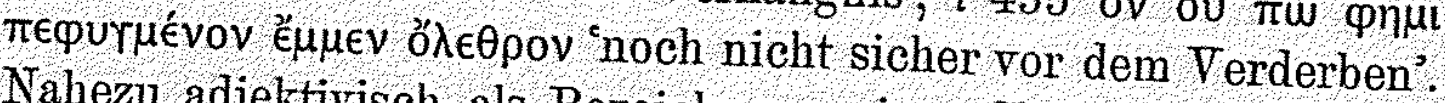
Nahezu adjektivisch als Bezeichnung einer Charaktereigenschaft

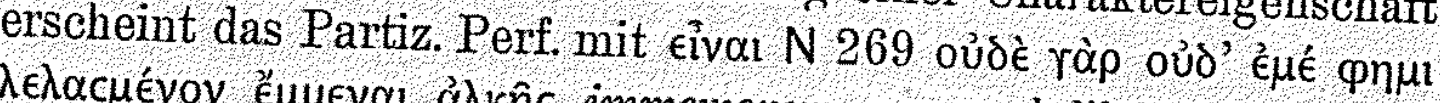

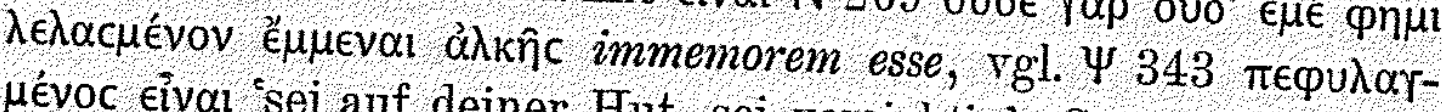
$\mu$ évoc eỉvol 'sei auf deiner Hut, sei vorsichtig'. So werden selbst Verbindungen möglich, wie $\times 219$ oú oi vôv étı $\gamma^{\prime}$ '́ctı $\pi \in \varphi u r$

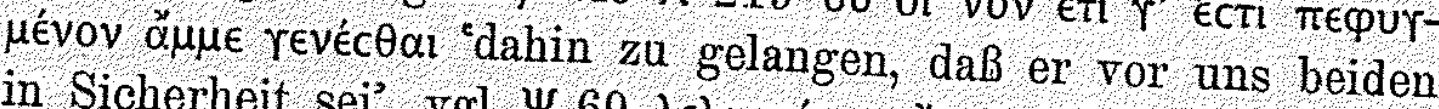
in Sicherheit sei, vgl. $\Psi 69 \lambda \in \lambda \alpha c \mu \in v_{0}$ é $\pi \lambda \in$ u.

Die Zeits tufe ergibt sich auch für den Inf. Perf, aus dem Zusammenhange der Rede. Zeitlos ist er in allgemeinen Sätzen,

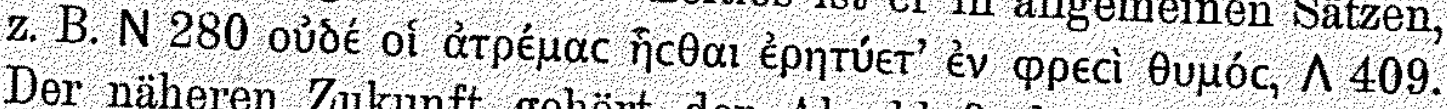
Der näheren Zukunft gehört der Abschluß der Handlung und

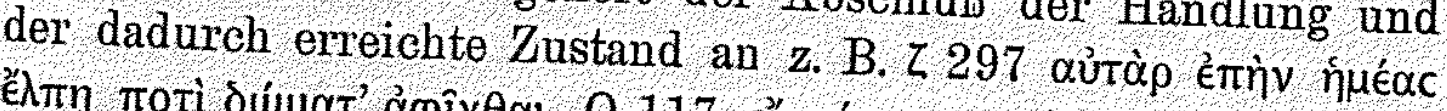

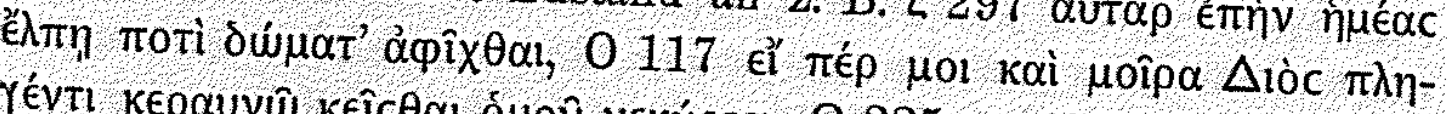

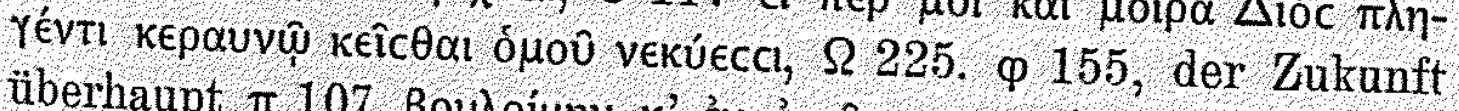

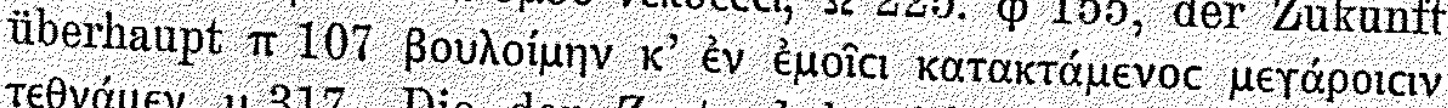

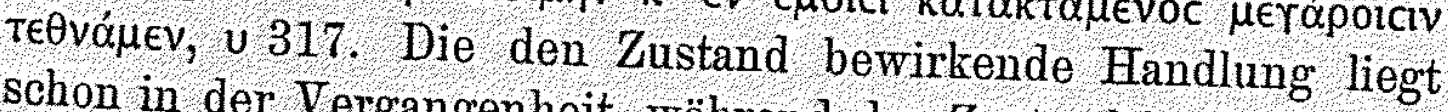
schon in der Vergangenheit, während der Zustand in die Gegen-

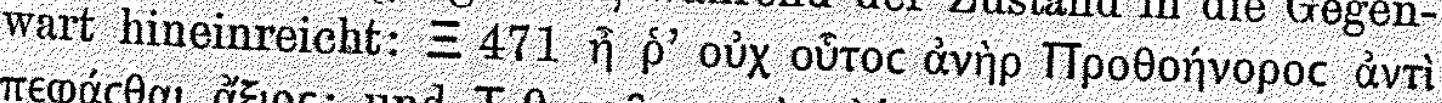

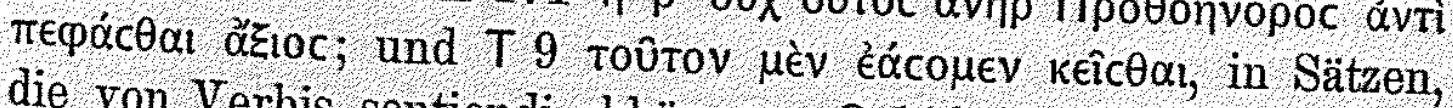

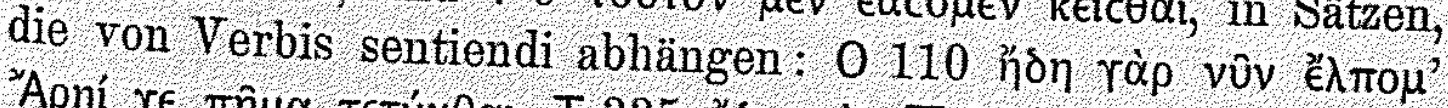

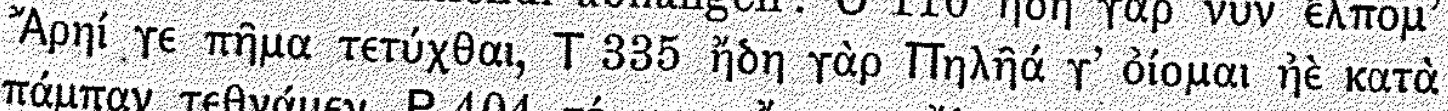

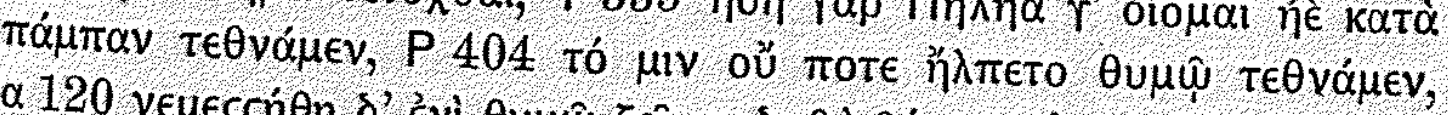

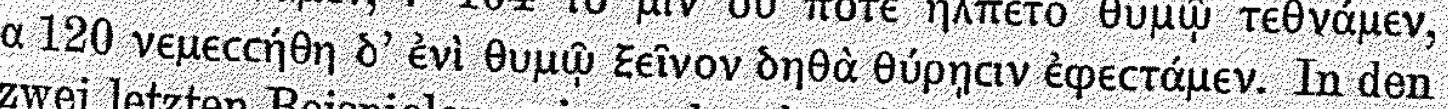
zwei letzten Beispielen, wie auch schon in den S. 257 rerzeichne-

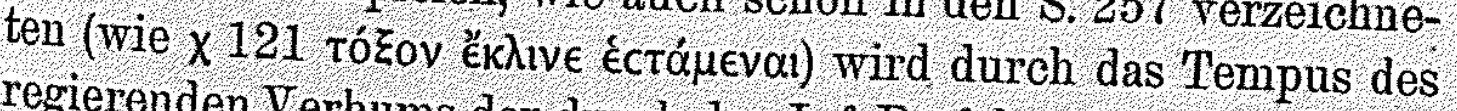
regierenden Verbums der durch den Inf. Perf. bezeichnete Zustand in die Vergangenheit gerückt. Die letzte Stufe der Entwicklung 
bezeichnen zwei Beispiele, in denen der Inf. Perf. in abhängiger Rede nach qaci so steht, daß der bezeichnete Zustand nicht mehr in die Gegenwart des Sprechenden hineinreicht, also als soge-

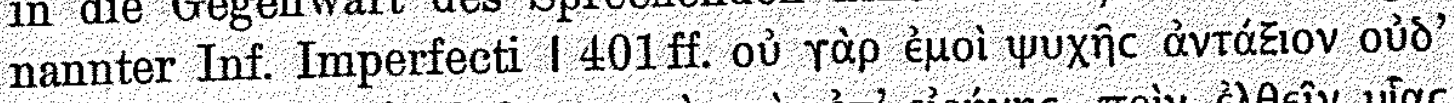

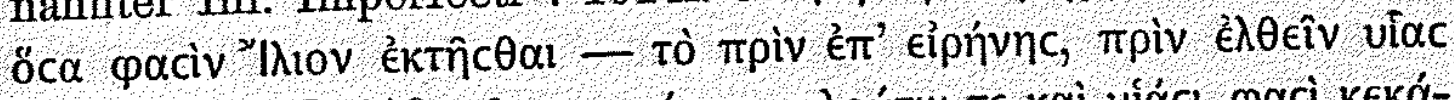

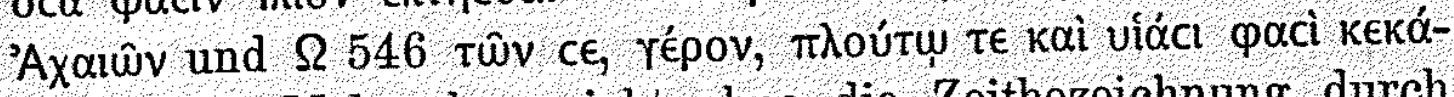
cөal, beide Male aber nicht ohne die Zeitbezeichnung durch $\pi \rho i v$, welche in $\Omega$ in dem einleitenden Satze 543 kal cé, répov,

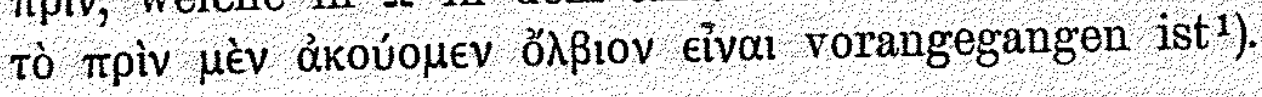

1) DaB der Gebrauch des Inf. Perf, während der Periode der homerischen Dichtung noch in fortschreitender Entwicklung begriffen gewesen ist, ergibt sich auch aus folgenden Beobachtuugen. Ein hohes Alter wird

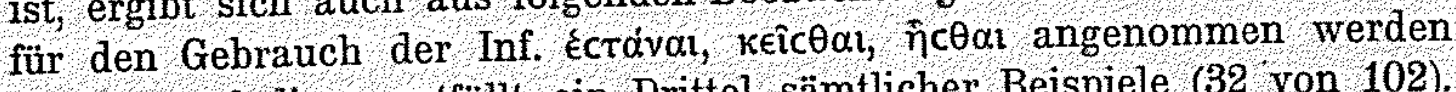
dürfen; auf diese entfällt ein Drittel sämtlicher Beispiele (32 von 102). Diesen stehen an Frequenz des Gebrauchs am nächsten $\tau \in \theta v \alpha \mu \in \nu$ ( 7 Beisp),

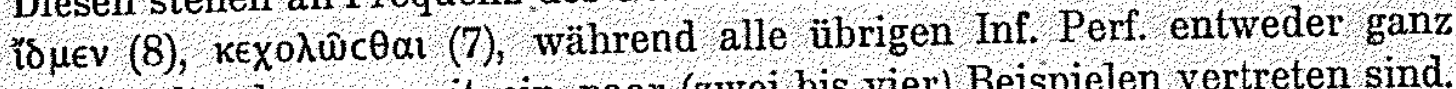
vereinzelt oder nur mit ein paar (zwei bis vier) Beispielen vertreten sind. Ferner bietet von den ihrem Hauptbestande nach sicher ältesten Gesängen

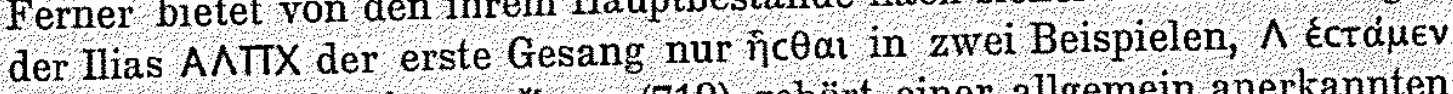
und keiçat in je einem, to $\mu \in v$ (719) gehört einer allgemein anerkannten

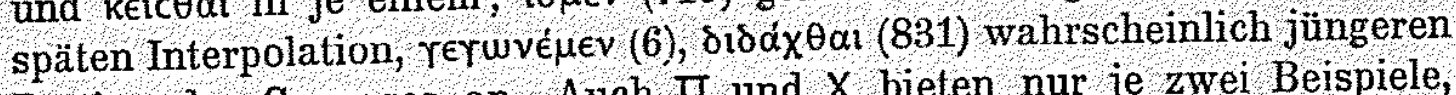
Partien des Gesanges an. Auch $\Pi$ und $X$ bieten nur je zwei Beispiele,

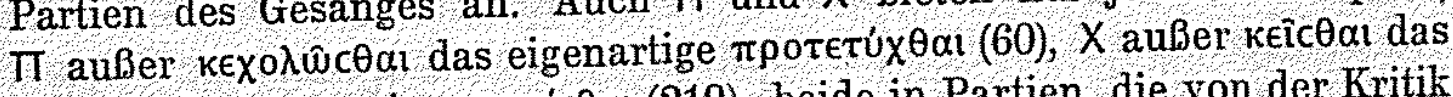

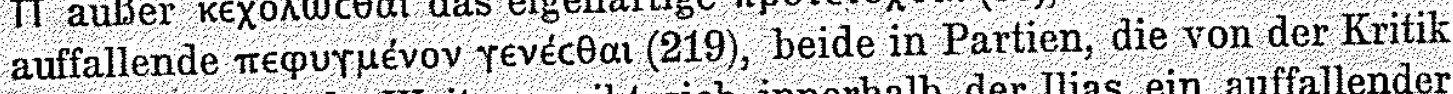
beanstandet sind. Weiter ergibt sich innerhalb der llias ein auffallender Unterschied des Gebrauchs zwischen den beiden Hälften des Epos: die erste weist 21, die zweite 47 Beispiele auf. Von den 21 Beispielen der

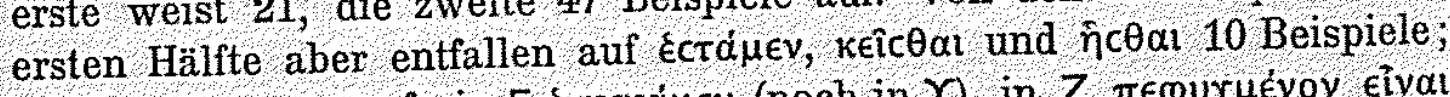

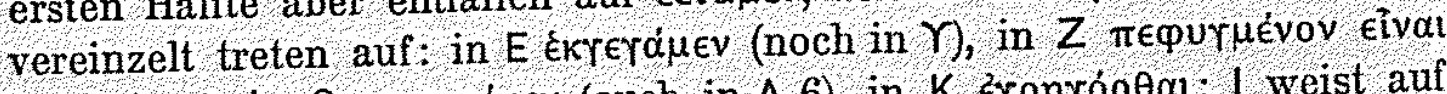

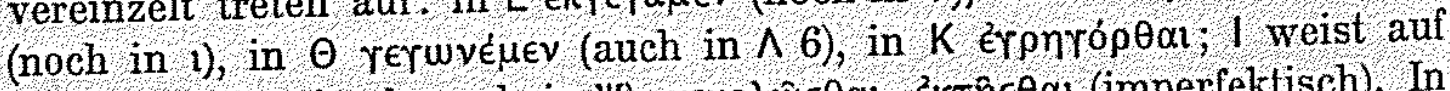

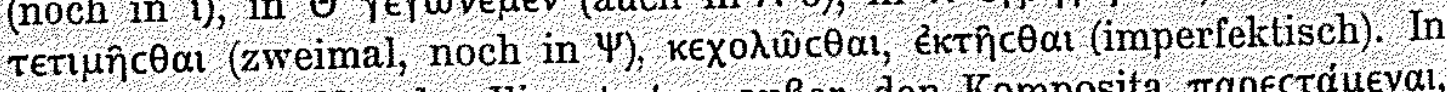

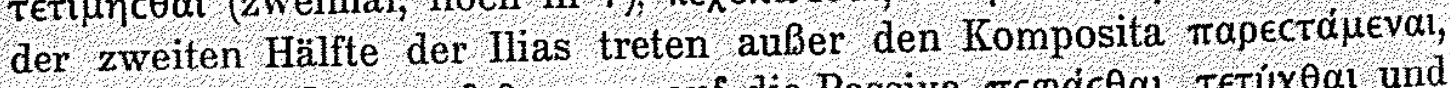

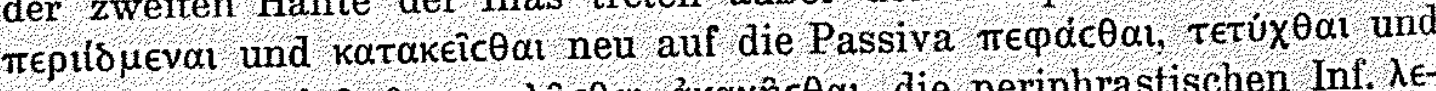

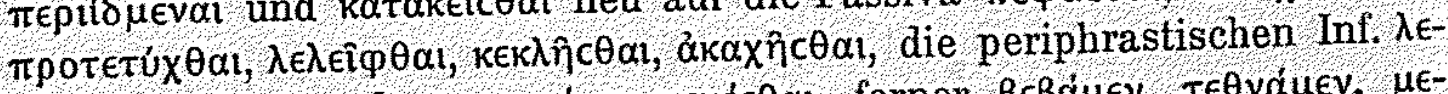

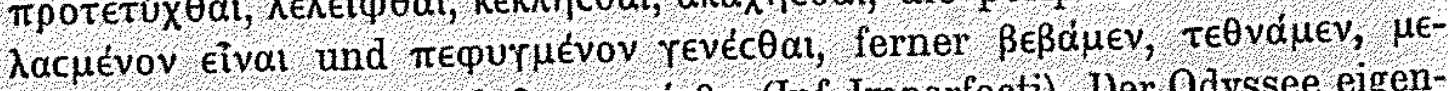

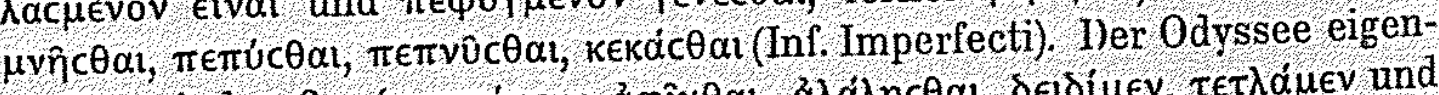

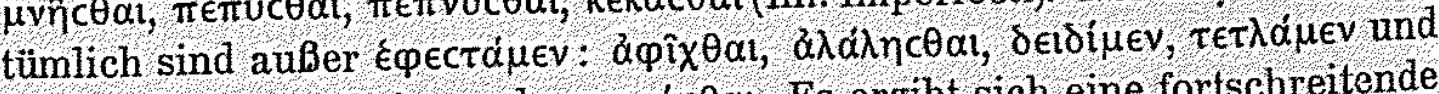

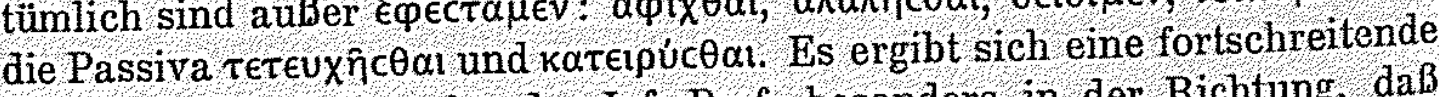
Zunahme des Gebrauchs des Inf. Perf. besonders in der Richtung, da $B$ er auf passive Perfekta (nebst $\tau \in \theta \vee \dot{\alpha} \mu \in v$ ) und solche aktive und mediale ausgedehnt wird, die einen geistigen oder einen Gemütszustand bezeichnen. - Noch mag bemerkt werden, daß in der ersten Hälfte der llias die Gesänge BГH ohne jedes Beispiel des Gebrauchs sind, während in der zweiten kein Gesang desselben entbehrt und die Gesänge NOPT $\Omega$ sogar mit je 5 bis 8 Beispielen vertreten sind. Der Gesang 1 steht denen der zweiten 
3. Die Aktionsart des Aorist bezeichnet man im Gegensatz zu der des Präsens treffend als punktuell und unterscheidet zunächst, je nachdem der Anfangs- oder der Schlußpunlt der Handlung herausgehoben wird, ingressive und effektive Aoriste. Dazu kommt nach Mutzbauer Die Grundlagen der Griech. Tempuslehre S. 11 ein dritter Typus, in welchem 'die ganze Handlung des Terbums als konzentrierte, in einen Moment zusammengefaßte, sozusagen als Mittelpunkt erscheint'. Diesen Typus hat dann Delbrück Vergl. Synt. 2, $237 \mathrm{f}$. als denjenigen bezeichnet, in welchem die Handlung punktualisiert erscheine, und näher dahin bestimmt, daß der Aorist im Vergleich mit der Handlung des Präs. nicht einen Anfangs- oder Endpunkt darstelle, sondern die ganze Handlung des Präs, aber in einen Punkt zusammenge-

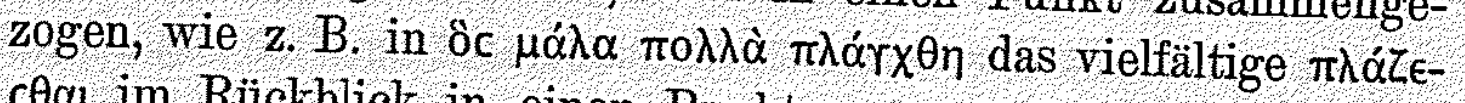
c $\theta$ al im Rückblick in einen Punkt zusammengezogen erscheint

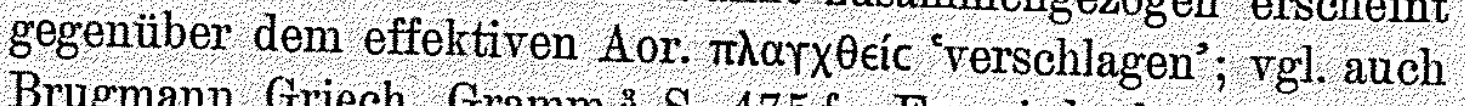
Brugmann Griech. Gramm. ${ }^{3}$ S. $475 \mathrm{f}$. Es wird aber nicht nur was in der Vergangenheit ofter vorgekommen ist, sondern auch was sich länger hingedehnt hat, im Aor. in einen Punkt zu-

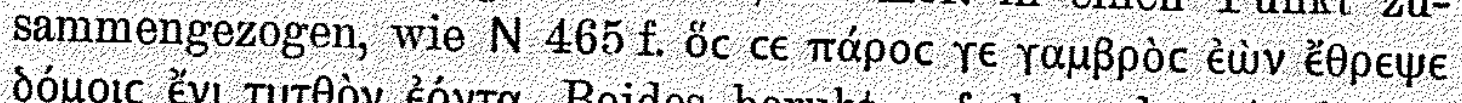

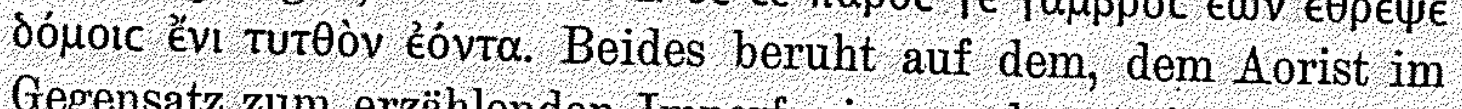
Gegensatz zum erzählenden Imperf. eigenen konstatierenden Gebrauch, welcher Wiederholung und Dauer der Handlung nicht ausdrückt, sondern ignoriert, vgl. Delbrïck a. 0. S. 283 und $302 \mathrm{ff}$.

$\mathrm{Da} B$ der Infin. Aor. vom Indikativ nur die Aktionsart, nicht aber die Zeitstufe übernahm, also nicht eine Handlung der Vergangenheit bezeichnete, ist schon deshalb selbstverständlich, weil er des auf die Vergangenheit weisenden Augments entbehrte. Zeitlos erweist sich der Inf. Aor. noch in einer Reihe von Beispielen, in denen er in Abhängigkeit namentlich von verbis sentiendi scheinbar die Bedeutung des Infin. Fut. hat. Dieser Gebrauch erklärt sich ohne weiteres, wenn er von $V$ erben und Wendungen abhängt, deren Begriff schon auf die Zukunft

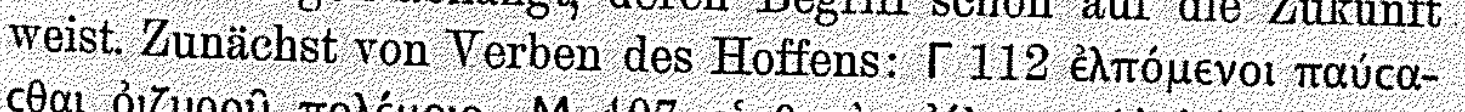

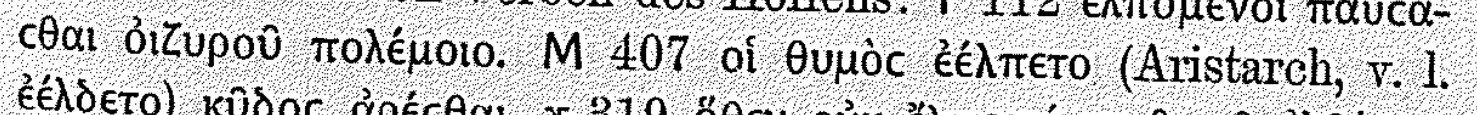

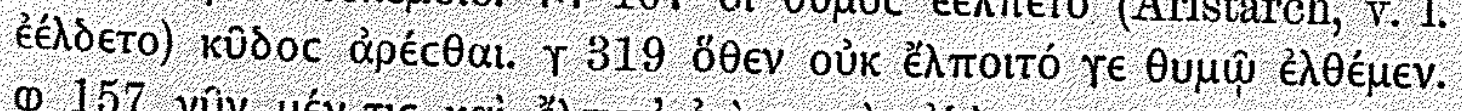

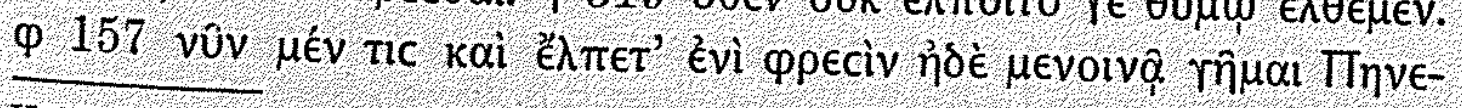

Hälfte dadurch näher, dáß er mit diesen die Passiva kexoגưc $\theta$ al und $\tau \in \tau$ $\mu$ ñceal teilt und das erste Beispiel des imperfektischen Gebrauchs des Inf. Perf. bietet, wovon ein zweites sich noch in $\Omega$ findet. 


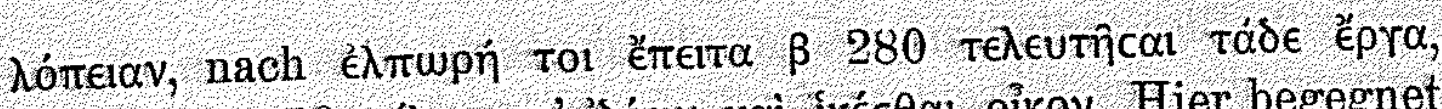

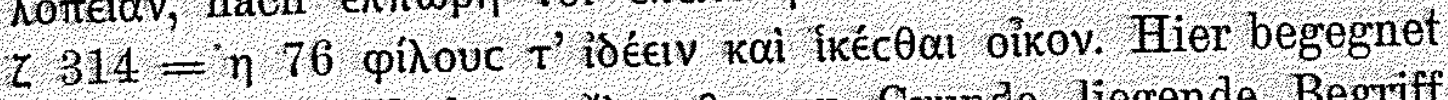
sich der dem Verbum é $\lambda \pi \epsilon c \theta$ al zu Grunde liegende Begriff 'wählen, wünschen' (vgl. L. Meyer Griech. Etym. 1, 488 f., Prellwitz Etym. Wtb. S. 92) mit der dativisch-futurisehen Richtung des Infin. und insbesondere der effektiven Bedeutung des Infin.

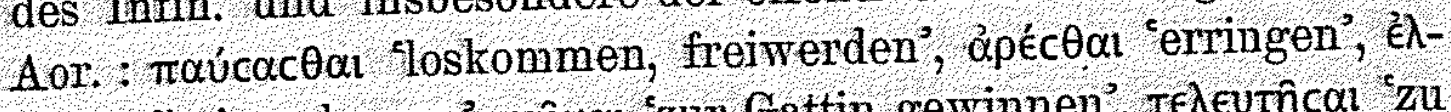

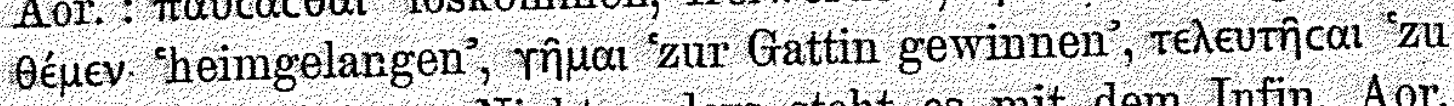
Ende führen'.) - Nicht anders steht es mit dem Infin. Aor.

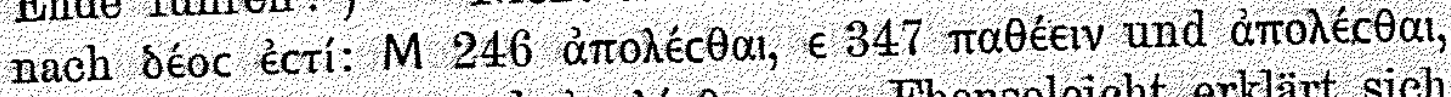

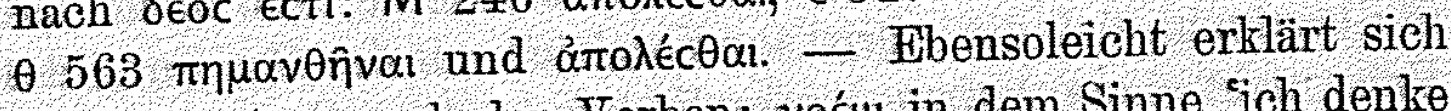
der Infin. Aor. nach den Verben. voéw in dem Sinne 'ich denke

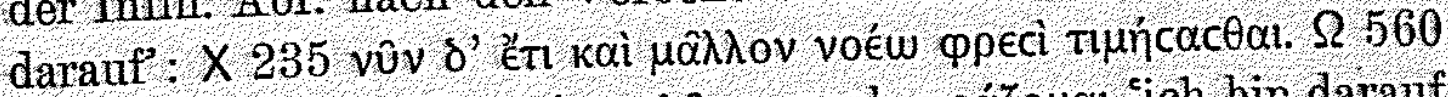

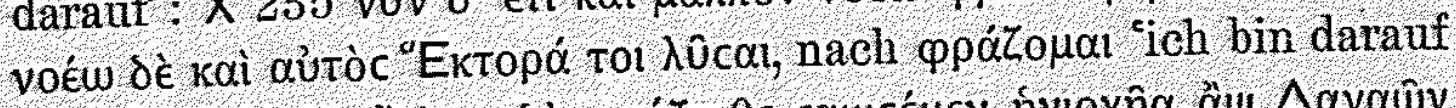

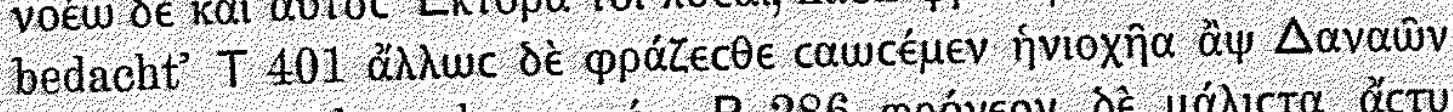

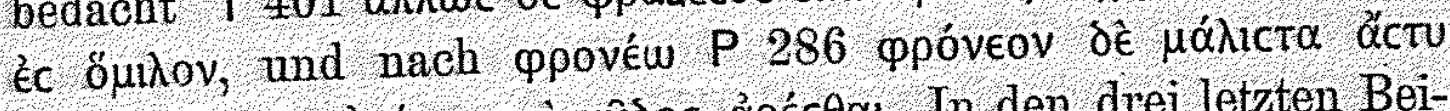

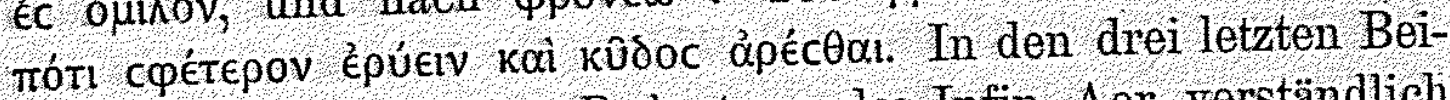
spielen ist die effektive Bedentung des Infin. Aor. verständlich

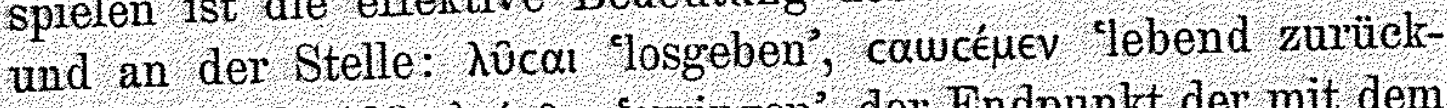
bringen', vgl. 403, ápeccoal 'erringen', der Endpunkt der mit dem Infin. Präs. épúeıv bezeiclneten Bemähungen, den Leichnam zu sich herüberzuziehen. Dagegen läßt in X 235 der Zusammenhang für den Tnfin. tıuńcacoal die effektive A uffassung ${ }^{2} \mathrm{zu}$ Ehren

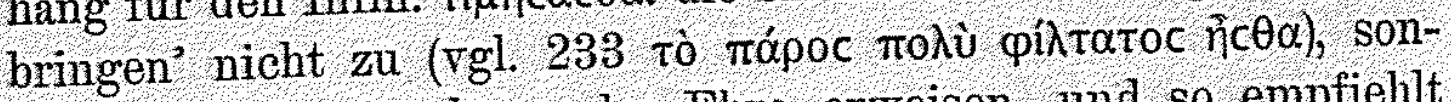
dern verlangt ein dauerndes Thre erweisen, und so empfiehlt

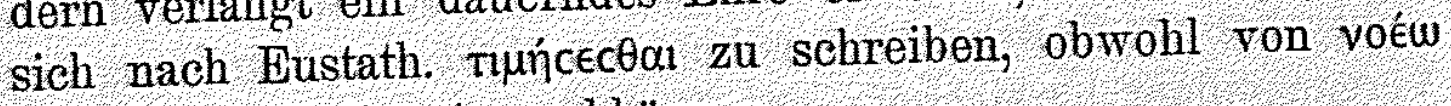
überall nur Infin. Aor. abhängen.

Auffallender ist der Inf. Aor. nach Verben des Schwörens in futurischem Sinne: X 119 Tpwciv $\delta^{\prime}$ âे $\mu \in t o ́ m i c \theta e$ Гepoúciov

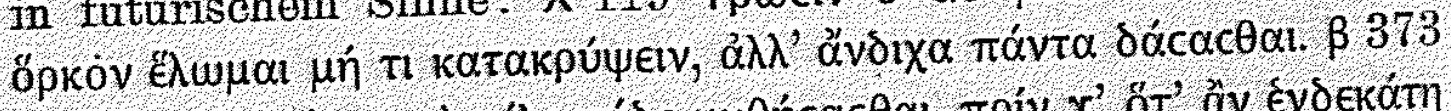

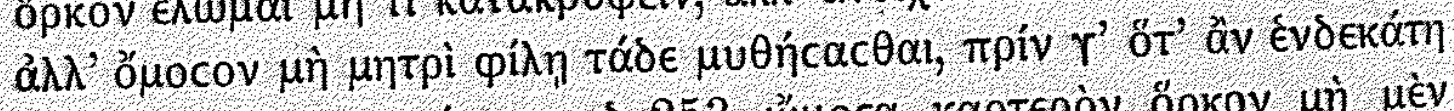

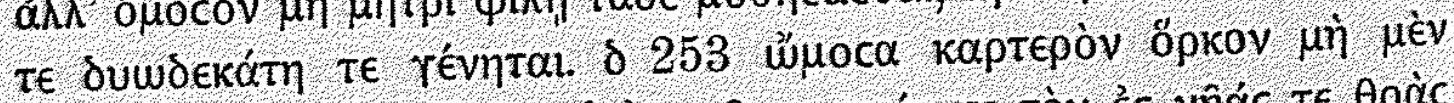

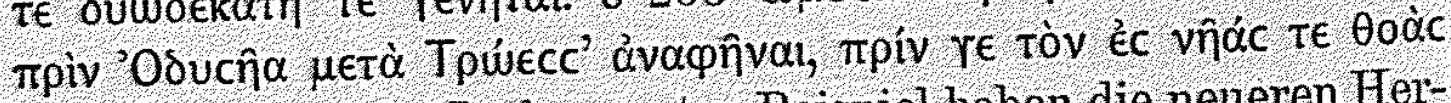

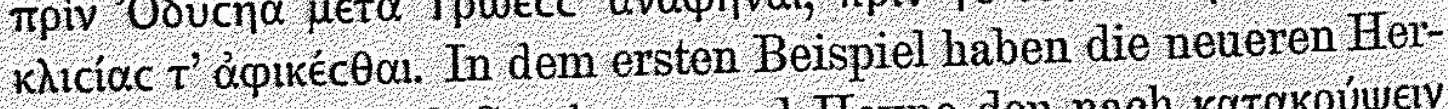
ausgeber meist nach Stephanos und Heyne den nach kaтakpúyeiv

1) In 0229 ist mit Ludwich nach der ältesten Odysseehandschrift G und Eustath. gegen La Roche Hom. Unters. II S. 99 vocrícelv zu schreiben; das in den übrigen Handschriften gelesene voctñcal ist in diese Stelle irrig

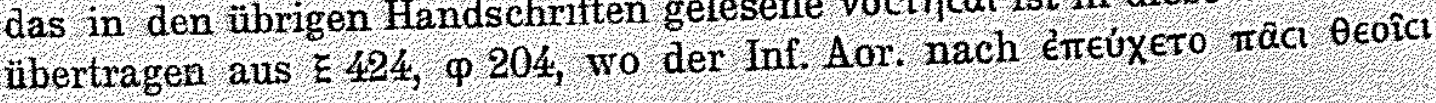
an der Stelle ist. 


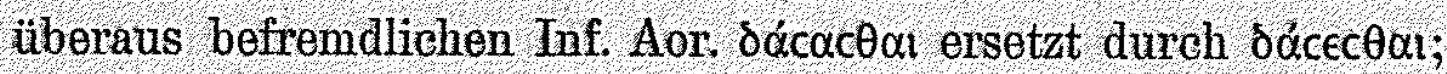
vielleicht ist Jácac $\theta$ al aus $\Sigma 511$ hierher geraten. Jedenfalls sind die Versuche, den Inf. A or. im Unterschiede vom Inf. Fut. zu erklären nicht überzeugend. Auch in B 373 kann man zunächst geneigt sein, $\mu u \theta$ ńcecoal als Lesart des Aristarch (Ludwich Ar. H. T. 1, 527) der handschriftlichen $\mu v \theta$ ńcaceal vorzuziehen, vgl. auch 0746 . Dagegen spottet in 0253 die Lesart àvapñval aller Versuche, dafür einen Inf. Fut. einzusetzen. Dies Beispiel hat aber mit dem vorhergehenden das Gemeinsame, daß ein Zeitpunkt, bis za welchem das àvaqiva nicht erfolgen soll, durch mpiv mit Inf. Aor. genau fixiert wird. Die gleiche Erscheinung findet sich in einem Teil der Handschr. E 287: àtà $\rho$ où Hêv

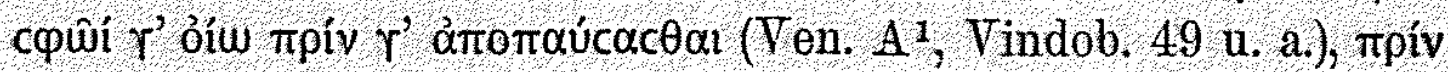

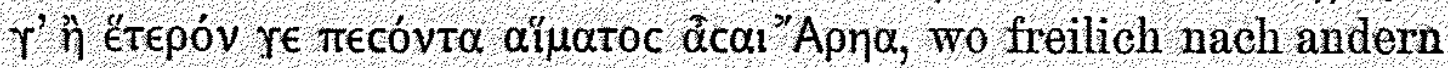

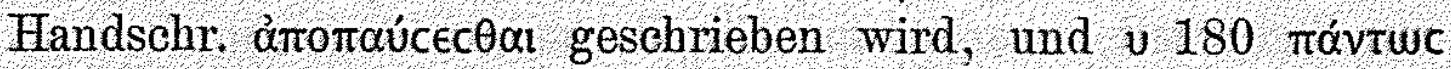

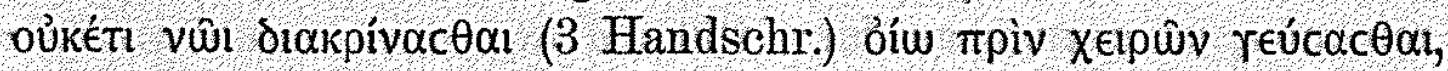

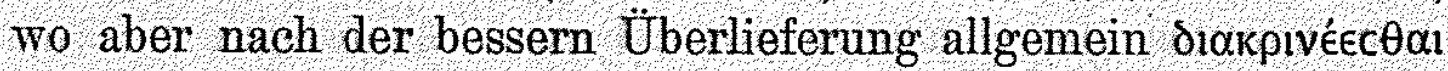
gelesen wird. Jedenfalls scheint in diesen Beispielen der Int. A or. nach den Verben des Schwörens und óíw mit der Konstruktion von mpiv mit Inf, Aor. derart im Zusammenhang zu stehen, daß der Eintritt beider Handlungen zeitlich zusammentreffend gedacht wird, und es ist dann wohl begreiflich, daß es dem Sprachgefühl wichtiger schien, den Tintritt der Handlung im Inf. Aor. zu bezeichnen (ávapnval 'zur Kenntnis zu bringen'), als die Zeitstufe der Zulkunft. - Auch in B 198 oủ

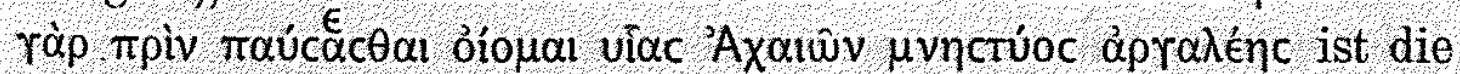
besser beglaubigte Lesart naúcacӨal, für welche La Roche Hom. Unters. II, 98 eintritt. Da hier aber der Wille der Freier zu deutlichem Ausdruck zu bringen war, so haben die Herausgeber mit Recht fast allgemein den Inf. Fut. geschrieben. ${ }^{1}$ )

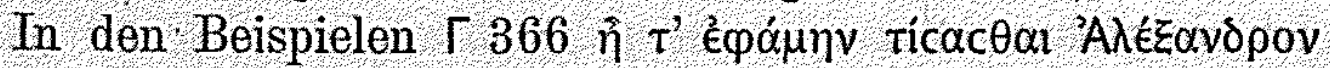

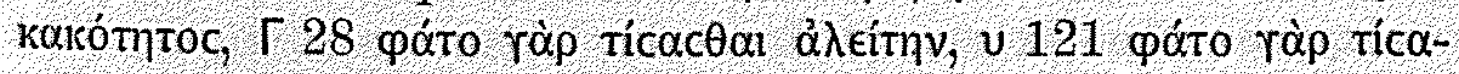
cac $\theta \alpha 1$ a $\lambda \in i t a c$ ist der Inf. Aor. besser beglaubigt, als der Inf.

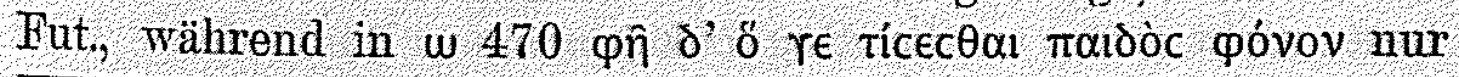

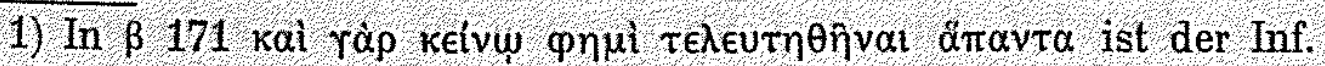
Aor. nicht mit La Roche in futurischem Sinne zu verstehen, sondern von der Vergangenheit, vgl. Capelle im Philol, 37 S. 120. - - In 2173 statt des

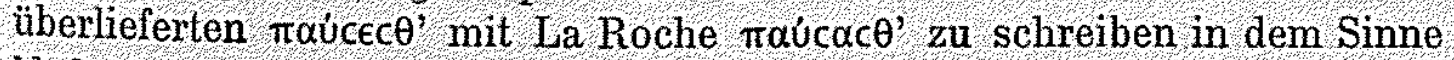
¿da $\beta$ meine Leiden jetzt ein Ende gefunden haben, wirklich aufhören werden', ist unnötig, da der Zusammenhang das noúceceal auf die Gegenwart beschränkt: jetzt aufhören werden. 
Vind. 50 rícac $\theta \alpha$ bietet. Wenn nun Menelaos $\Gamma 366$ die Worte

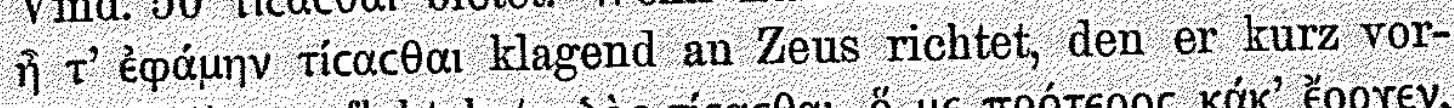

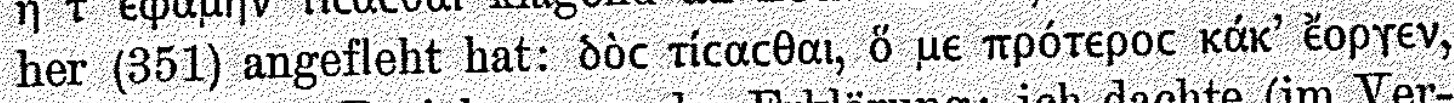
so führt diese Beziehung zu der Erklärung: ich dachte (im Vertrauen auf deine Gerechtigkeit, die ich angerufen) die Strafe zu vollziehen (effektiv gedacht: zum Vollzug der Strafe zu gelangen). Die andere, von Leaf in der Ausgabe vertretene Erklärung : $I$ thought, when dealing the blow, that I had (now) got my vengeance, würde hier zwar passen, weniger dagegen $\Gamma 28$, wo lediglich der Anblick des Paris in Menelaos den Gedanken der Rache erregt, und am wenigsten v 121, wo Odysseus aus den auf seine Bitte von Zeus gesendeten Wahrzeichen die Hoffnung schöpft, daß die geplante (aber erst am Abend des Tages vollzogene) Rache gelingen werde. Die Möglichkeit, etwas, was man mit Sicherheit erwartet, in Aor. als bereits eingetreten zu be-

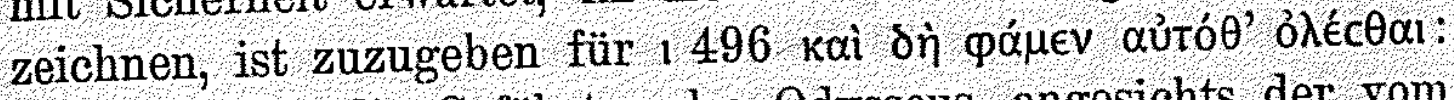
hier konnten die Gefährten des Odysseus angesichts der rom Kyklopen unmittelbar drohenden Gefahr sagen: whó $\mu \in \theta \alpha$ ' wir

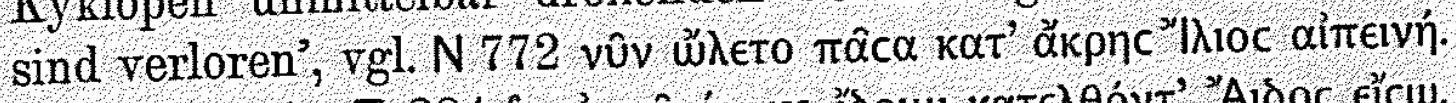

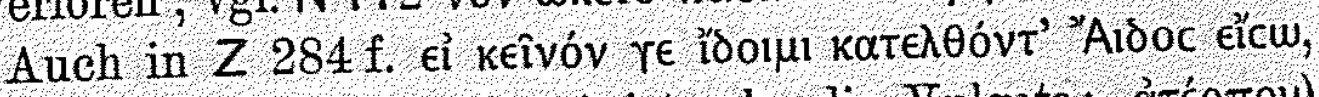

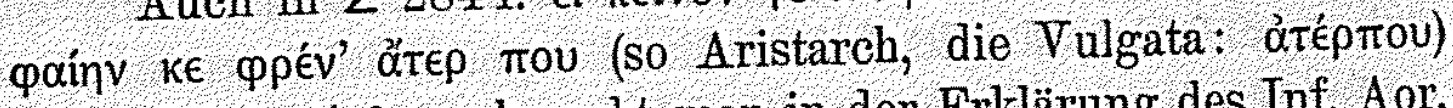

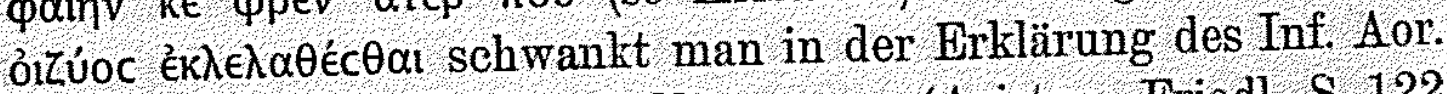

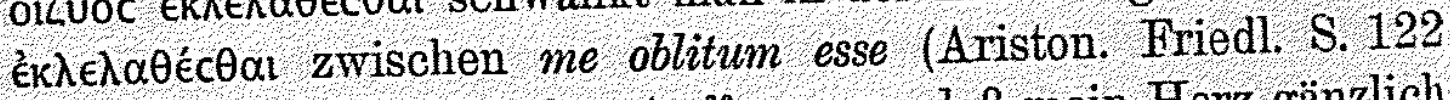
ek $\lambda \in \lambda \hat{\eta}(\theta \alpha i)$ und futurischer Auffassung: daß mein Herz gänzlich vergessen werde. Wäre nun qaínv ke zu verstehen: so könnte (oder würde) ich sagen, so würde ék $\lambda \in \lambda \alpha \theta^{\prime} e c \theta \alpha$ l den Ind. Aor. der direkten Rede vertretend zu fassen sein: bei mir sei völliges Vergessen eingetreten, ich dächte nicht mehr daran. Ist paínv

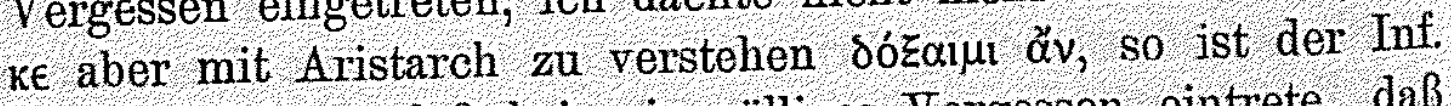
Aor. zu fassen: daß bei mir völliges Vergessen eintrete, daß

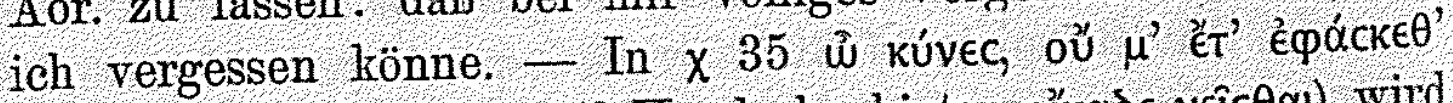

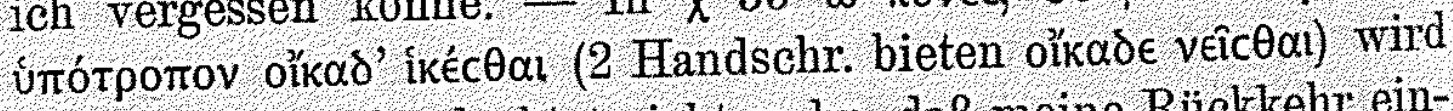
der Sinn sein: ihr dachtet nicht mehr, daß meine Rückkehr eintrete, nicht mehr an die Möglichkeit meiner Rückkehr.

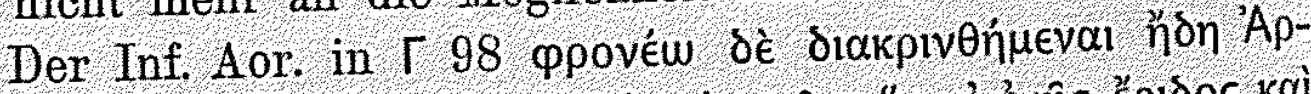

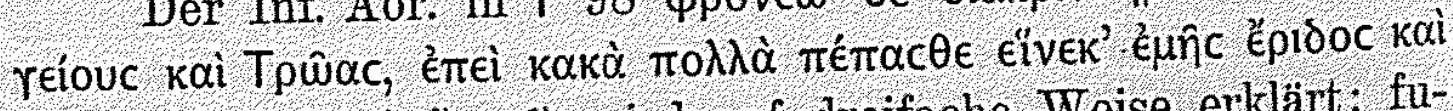

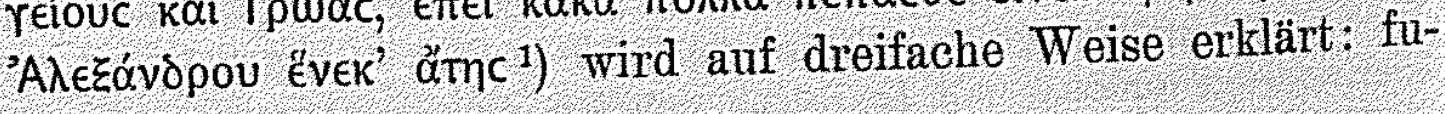

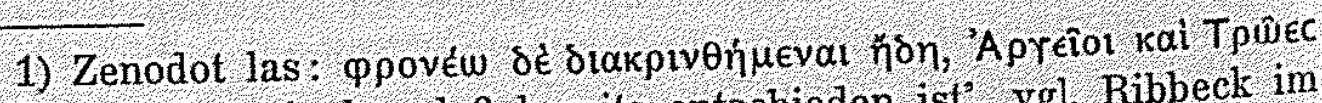
und erklärte: 'ich glaube, daß bereits entschieden ist', vgl. Ribbeck im Philol. 9 S. 148; diese Lesart und Erklärung wurde aber von Aristarch 
Aktionsart u. Zeitstufe der Infinitive in den homerischen Gedichten. 281

turisch von Gapelle: ich denke, daß nunmehr die Scheidung sich vollziehe zwischen Argivern und Troern' (als A usdruck zuversichtlicher Erwartung des Eintritts). Leaf stellt zwei Möglichbeiten der Erklärung auf, entweder: $M y$ mind is, that Argives and Troes be at once separated i. e. I desire to see them separated, oder: I deem, that they are already separated, i. e. I accept the challence, and think that an end has thereby been put to the war. Dieser letzteren Auffassung steht entgegen, daß die Worte 102

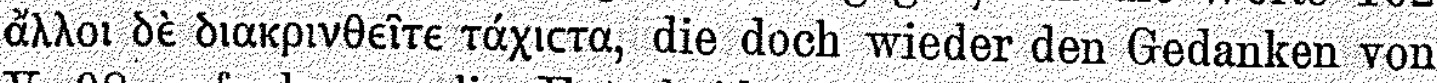
V. 98 aufnehmen, die Entscheidung des Zweikampfes voraussetzen, nach der beide Völker in Frieden sich scheiden werden. Die futurische Auffassung des Inf. Aor. aber wird unwahrscheinlich durch die Bedeutung des Verbums $\varphi \rho o v e ́ w$, welches bei Homer als ein einfaches 'denken, meinen' nicht nachweisbar ist, sondern außer 'erwägen, bedenken' vorzugsweise bedeutet: seine Gedanken auf etwas richten, was man erstrebt, hofft, wünscht. So scheint die Stelle im Sinne der ersten Erklärung von Leaf gefaßt werden zu müssen: meine Meinung geht dahin, daß Argiver und Troer nunmehr sich scheiden, d. i. in Frieden auseinandergehen (sollen), nachdem ihr so viele Leiden erduldet habt, womit Menelaos, wie die Schol. Townl: Maaß V S. 103 bemerken, betont, daß er durch das Mitleid mit den durch den Krieg hart geplagten Völkern sich znr Annahme des Zweikampfes bestimmen lasse.

Das einzige Beispiel eines futurischen Inf. Aor. in eigent-

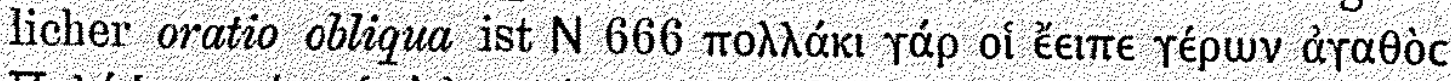

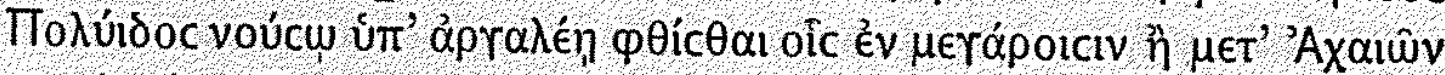

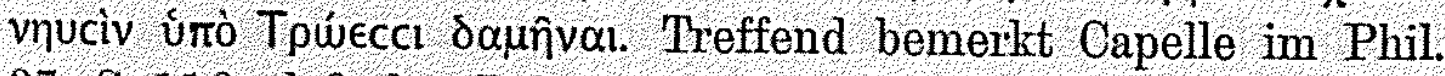
37, S. 116, daß der Inf. Aor, in bezug auf die Zukunft hier besonders passend stehe, weil er die Verwirklichung der Tatsache (als effektiver Aor.) lräftiger und bestimmter hinstelle, als der Inf. Fut. tun würde, was dem Tone zuversichtlicher Weissagung: durchaus entspreche, und vergleicht $\delta 561 \mathrm{f}$. und $\mathrm{k} 472 \mathrm{f}$, wo von Gécqatóv éct Infinitive Aor. abhängen, wie von $\mu$ oîpa und díca. Noch näher aber liegt der Vergleich von 1412 ff, wo A chill den Inhalt der ihm von seiner Mutter verkündigten Weissagung

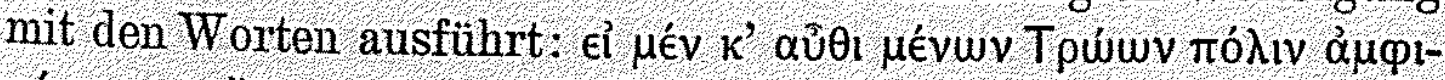

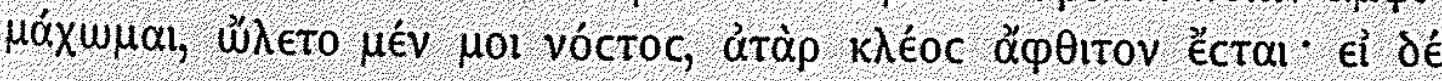

als dem homerischen Gebrauch von biakpivec $\theta$ al widersprechend mit Recht zurückgewiesen. 


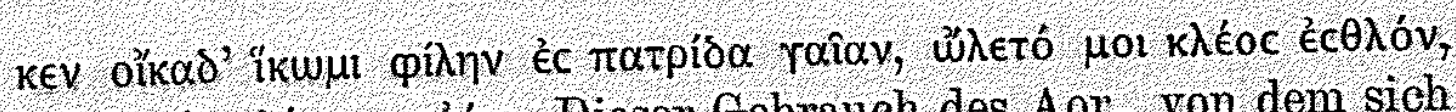
ėmi Snpòv dé nol aiúv. Dieser Gebrauch des Aor, von dem sich bei Homer nur noch das Beispiel $\Delta 161$ findet, gehört zu den Fällen, wo nach Bragmann Griech. Gramm. 3 S. 490 f. rgl. Delbrück Vergl. Syntax II S, $285 \mathrm{f}$, der Zeitpunkt der A oristhandlung von einer angenommenen Gegenwart aus bestimmt ist, und zwar 'so, daß der Sprechende eine Situation fingiert und gegenüber der durch einen Bedingungssatz gegebenen Voraussetzung ein Breignis als bereits eingetreten erscheinen läßt’ : 'dann ist mir die Heimkehr verloren'. Vgl. auch 1496 oben S. 263. Die inhaltliche Übereinstimmung von $1412 \mathrm{ff}$. mit N $666 \mathrm{ff}$. ist nicht zu verkemnen: den dort in den Bedingungssätzen enthaltenen Voraussetzungen entsprechen hier die lokalen Bestim-

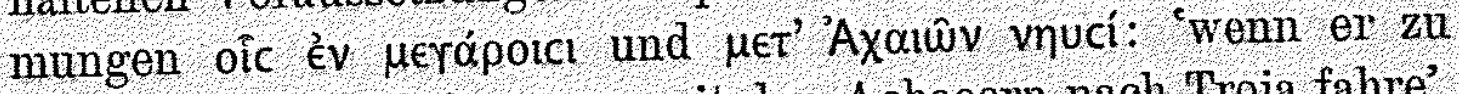
Hause bleibe' und 'wenn er mit den Achaeern nach Troja fahre'.

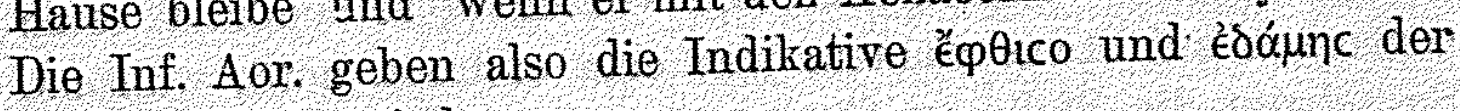
direkten Rede wieder.

Vereinzelt findet sich auch ein Beispiel, daß ron einem Verbum des Versprechens ein Inf. Aor. in futurischem Sinne

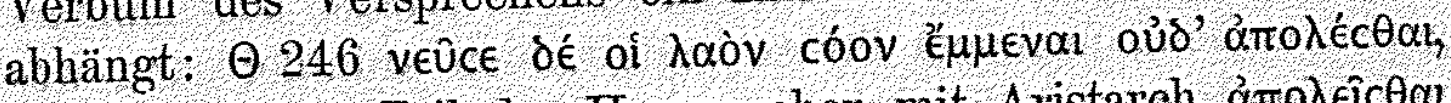

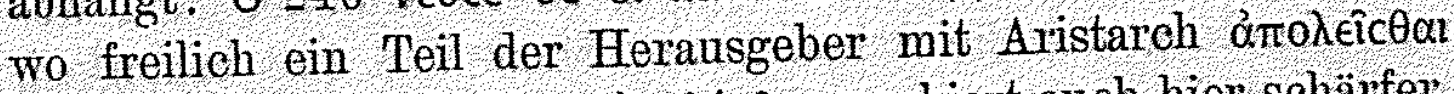

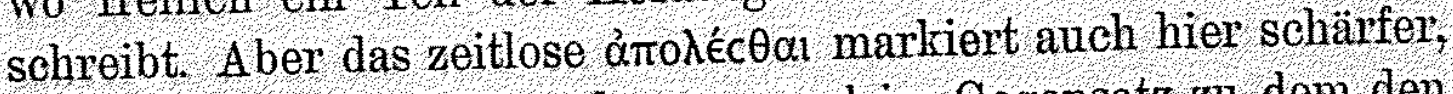

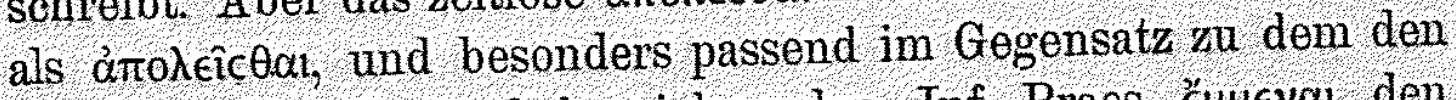
fortdauernden Zustand bezeichnenden Inf. Praes. Éujeval den Eintritt der Handlung: 'daß das Tolk erhalten bleibe und nicht

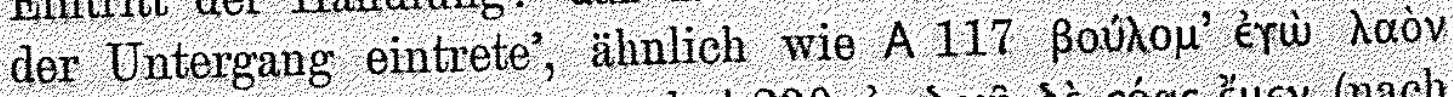

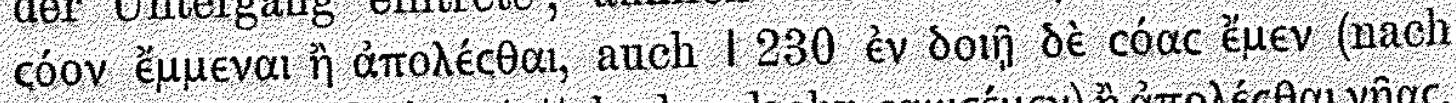
Bentleys Emendation statt des handschr. caucé $\mu \in v$ ) h̀ ámoléc $\theta \alpha ı$ vîac.

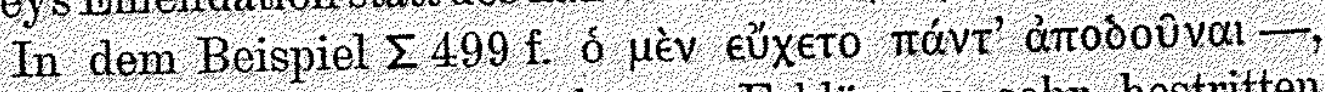
ó $\delta$ 'ávaíveto undèv é $\lambda \in ́ c \theta a l$, dessen Errklärung sehr bestritten ist, legen manche, wie auch Delbrück Tergl. Synt. 2, 472, 1, den Infinitiven futurische Bedeutung bei, Andere präteritale, rgl. Ameis-Hentze Anhang zur llias 6, 162 .

Es sind etwa zwanzig; auf beide Epen sich ziemlich gleichmäßig verteilende Beispiele, in denen wir den Gebrauch des Inf. Aor in futurischem Sinne festgestellt haben. Ton diesen zeigen nur drei (E 287. O 246, X 35) die Konstruktion des Acc. c. Inf., die übrigen den einfachen Infinitiv. Das einzige Beispiel erzählter Rede ist N 666. Ein solcher Inf. Aor. in futurischem Sinne wird zuerst in Abhängigkeit von Verben verwendet sein, 


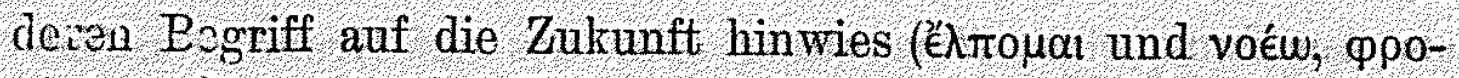
véw, $q \rho u ̈ z o \mu a$ in der Bedeutung bedacht sein auf, die Absicht liaken'). Dieser Gebrauch mag noch in die Zeiten zurückreichen, in welehen der Inf. Fut noch nicht völlig ausgebildet war, und neben diesem sich später noch behauptet haben, wenn es galt den Eintritt der Handlung schärfer zu betonen, als die Zeitstufe. Jünger scheint der Gebrauch zu sein nach Verben des Glaubens und Meinens: er findet sich in der llias nur in den Gesängen TEZ. Die Gesänge AATX weisen überhaupt kein Beispiel eines futurischen Inf. Aor. auf.

Wir wenden uns nun zu dem Gebrauch des Inf. Aor. in präteritaler Bedeutung. Tch gebe zunächst eine Übersicht sämtlicher Beispiele. Der Inf. Aor. steht präterital: im Acc. c.

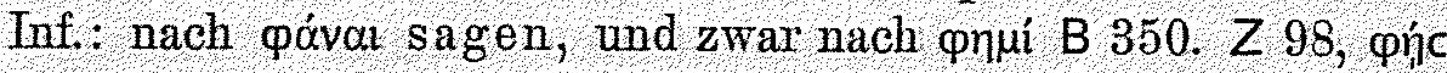
P 174, ké qaínc Г 393, qaci $\triangle$ 375. Ф 160. a 220. r 85. 188.

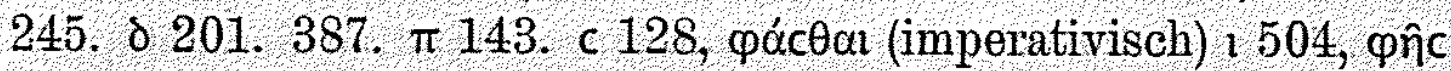

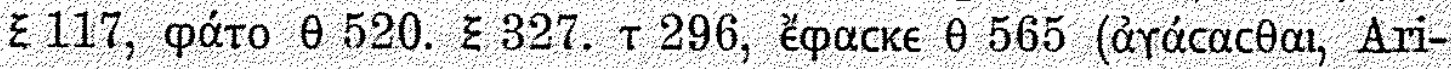
starch árácec $\theta a i)$. v $173(=\theta 565)$, nach qával glauben, und

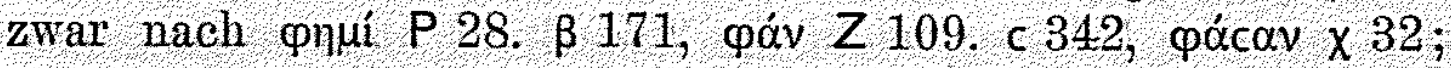

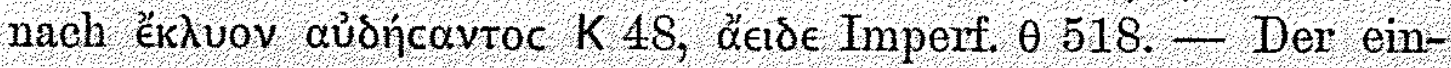

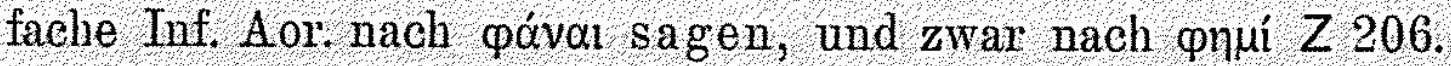
Ө 239. 1 329 (Inf. zu ergänzen). Y 187. o 141. т 380. X 314,

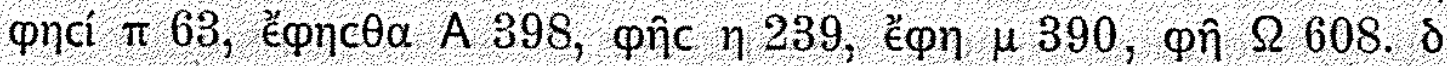

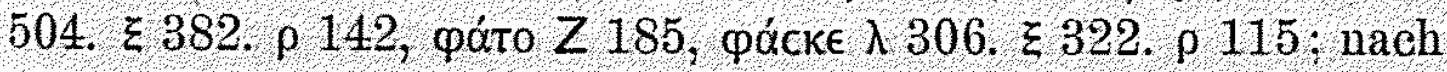

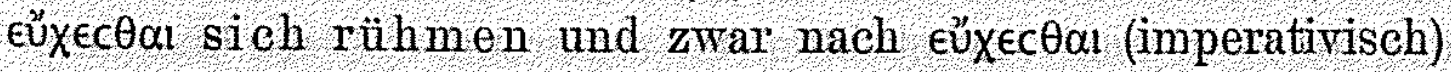

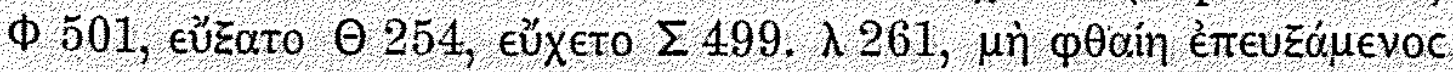

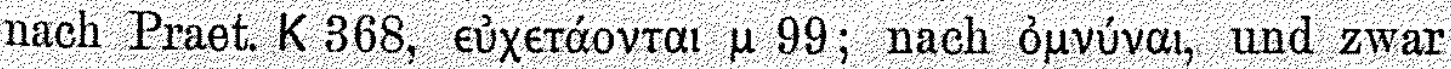

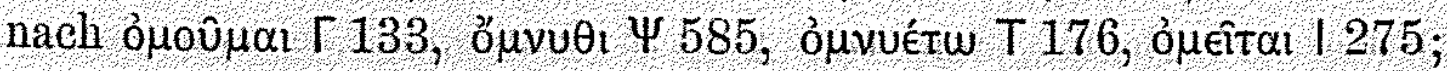
nach ávaíveto $\Sigma 500$, nach cteútal er behauptet o 525 . Im Acc. c. Inf. nach óíely, und zwar nach óiw A 558 . K 551. $=455$.

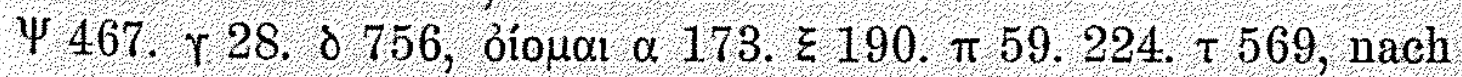

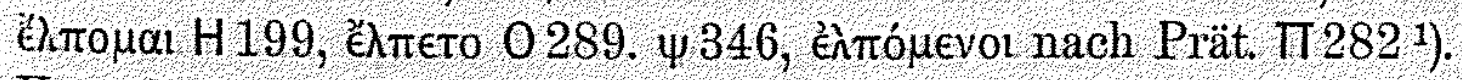
Von diesen 74 Beispielen gehören der Ilias 32, der Odyssee aber 42 an. Der Gebrauch nimmt also in der Odyssee ganz erheblich zu. Zu den aufgezählten präteritalen Infinitiven Aor. nach verbis dicendi und sentiendi kommen noch die nach $\mu \in \operatorname{l} \lambda \omega$

1) Vgl. La Roche Hom. Unters. I S. 83 ff, der über einige Stellen anders urteilt. In 1645 und $r 196$ den Inf. Aor. präterital zu fassen sehe ich keinen zwingenden Grund. In T 22 kann der Inf. Aor, präterital gefaßt werden. In E 190, wo er die allein überlieferte Lesart mpoidueı

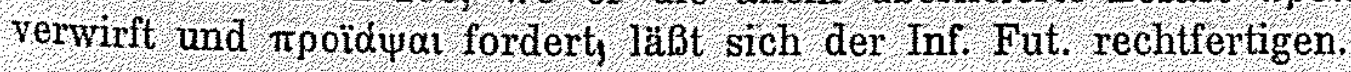


als Ausdruck einer Vermutung oder des auf Grund von Tatsachen Wahrscheinlichen: N 776, $\Sigma$ 362. Ф 83. $\Omega 46 . \delta 274$. 378. ₹ 134, auch 0 181, wenn mit La Roche aráccaceal statt áráccec $\theta$ al zu schreiben ist. Dieser Gebrauch, der sich in keinem der ältesten Teile des Epos findet, ist vermutlich jünger. - Von passiven Aoristen mit passiver Bedeutung findet sich nur das

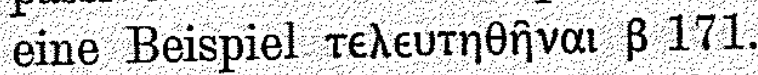

Nach Delbrück Vergl. Synt. II, 274 ist die, Vorstellung der Zeitstufe der Vergangenheit in den Inf. des Aor, wie des Praes, durch Übertragung hineingekommen, indem 'man bei Infinitiven, die von verbis dicendi oder sentiendi abhängig sind, noch sehr deutlich die Vorstellung haben kann, daß sie bei Umwandlung der Redeformen aus Augmentformen zu Infinitiven geworden sind', und Brugmann Griech. Gramm. S, 521 sagt: 'Die von verba sentiendi oder declarandi abhängigen Infinitive erscheinen, gleich wie die entsprechenden Optative der obliquen Rede, als Reflexe der Indikative der direkten Rede?. Tersuchen wir näher nachzuw eisen, unter welchen besonderen Bedingungen sich mit dem Inf. Aor. leicht die Vorstellung einer vergangenen Handlung verknüpfen konnte. Die Übertragung der Zeitstufe des Ind. Aor. auf den Inf. wird zunächst im Wechselverkehr von Rede und Gegenrede sich vollzogen haben und dann erst bei Wiedergabe fremder vergangener Rede in Anwendung gekommen sein. Überwiegt doch auch der praeteritale Gebrauch des Inf. Aor. nach Hauptzeiten der regierenden Verba überhaupt den nach historischen Zeiten (43 Beisp. gegen 31 ), und während ron dem Gesamtgebrauch der Mias (32 Beisp) nur etwa ein Drittel $(11$ Beisp) den Inf. Aor. in Abhängigkeit von einem historischen Tempus zeigt, nimmt dieser Gebrauch in der Odyssee so zu, daß er sich bis etwa zur Hälfte der Beispiele steigert $(20: 42)$.

Ohne weiteres übertrug sich die Zeitstufe des Ind. Aor. auf den Inf, wenn der Sprechende eine im Ind. Aor. getane Außerung des Mitunterredenden aufnahm und in abhängiger Form wiedergab, wie Hektor z. B. P 174 den Vorwurf des Glaukos

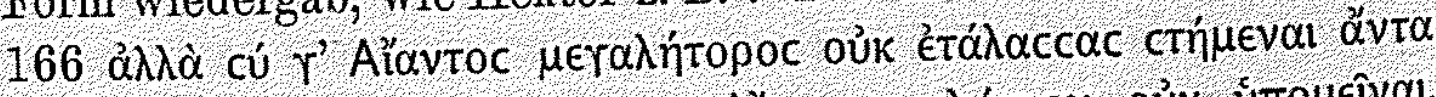

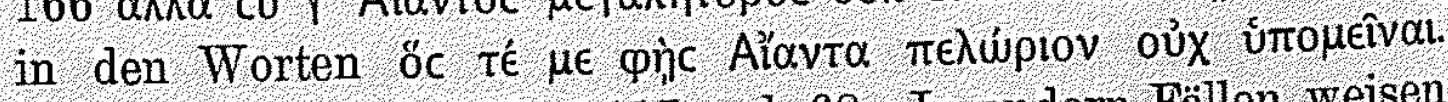
Ebenso $\eta 329$ vgl. 152, $₹ 117 \mathrm{vgl}$. 68. In andern Fällen weisen die vorhergehenden Worte des Sprechenden auf die Vergangenheit, sodaß in Zusammenhange mit diesen der Inf. Aor. von 
Aktionsart u. Zeitstufe der Infinitive in den homerischen Gedichten. 285

selbst in die gleiche Zeitsphäre gerückt wird, wie A 557 j̇epín

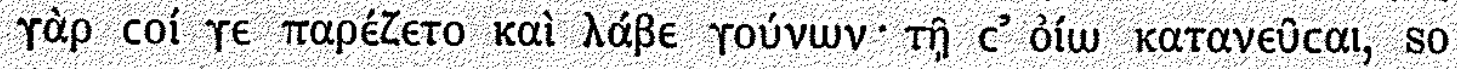
$\Psi 465 \mathrm{ff}$. K 546. 551 . a $171 \mathrm{ff}, 1502 \mathrm{ff}$. Insbesondere wird auch bei der beliebten Form, durch $\varphi \eta \mu \mathrm{i}$ mit Infinitivkonstruktion eine Tatsache der Vergangenheit nachdrücklich in Erinnerung zu bringen oder festzustellen, die in 11 Beispielen vorliegt, die im Inf, Aor. bezeichnete Handlung meist durch den Zusammenhang mit dem Vorhergehenden in die Zeitsphäre der Vergangen-

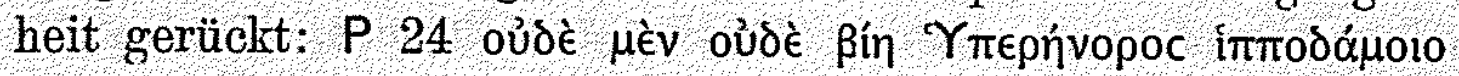

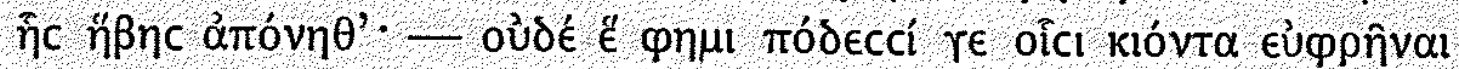

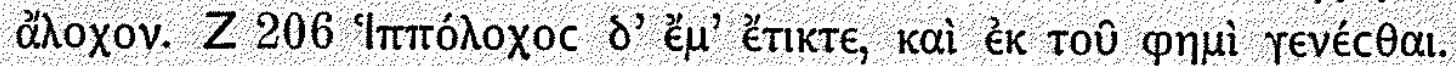
B $349 \mathrm{f}$. I 328f; anderwärts durch besondere Zeitangaben, wie

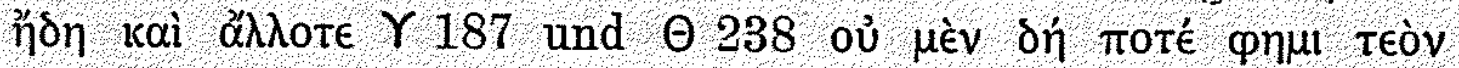

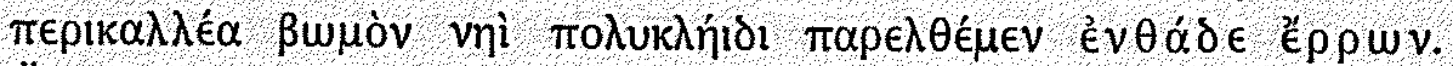
Überwiegt bei diesen Inf. A or. die effektive Aktionsart des Ind, so finden sich doch auch Beispiele der punktualisierten A ktions-

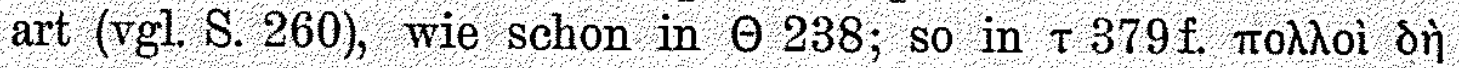

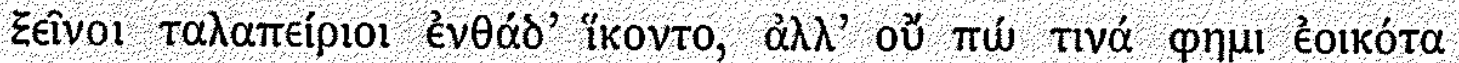

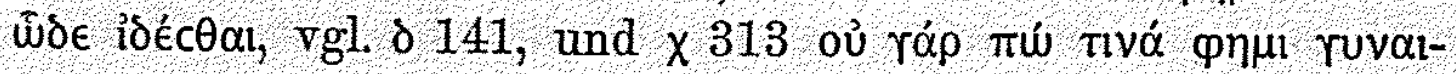

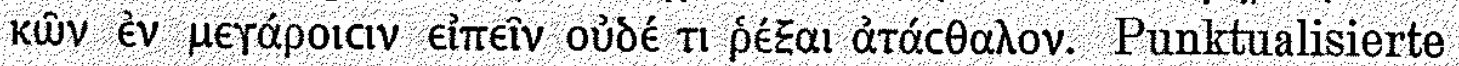
Aktion im Inf. Aor. liegt außerdem vor in den Beispielen: nach

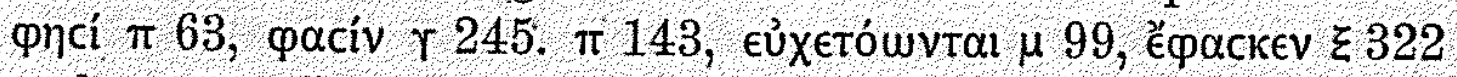

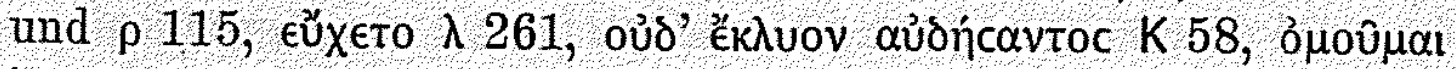
$1133=275=T 176$. Noch sind die Beispiele herauszuheben, in denen der Inf. Aor. ron eben Geschehenem verwendet wird, entsprechend dem bei Homer keineswegs so seltenen Gebrauch des Ind. Aor, das Ergebnis einer eben vollzogenen Handlung

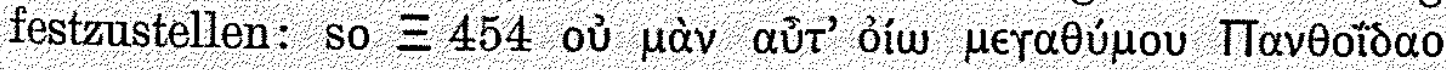

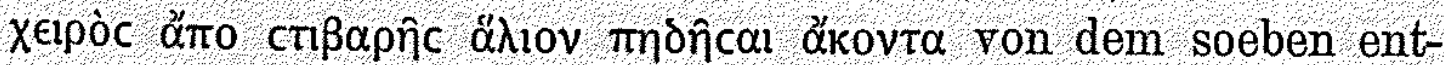
sandten Speer, ebenso nach oíw $\Psi 467$, nach qnuí Z 98, nach

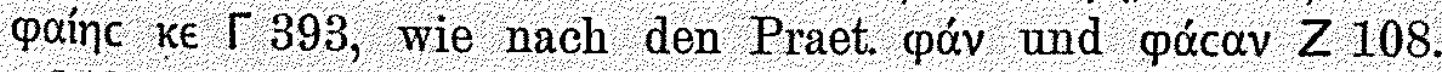
c 342. $\times 31$.

Eine bedeutende Rolle spielen in den verzeichneten Beispielen die von der ersten Person Sing. qnui und ólw abhängigen Infinitivkonstruktionen: sie finden sich so zahlreich, daß sie fast ein Drittel des Gesamtgebrauchs ausmachen. Bei diesen Beispielen begreift sich besonders leicht, wie die präteritale Bedeutung des Ind. Aor. bei abhängiger Form sich unmittelbar auf den Inf. Aor. übertrug. Denn diesen Konstrulktionen lagen ursprünglich parataktische Gedankenfolgen zu Grunde, wie N 153 


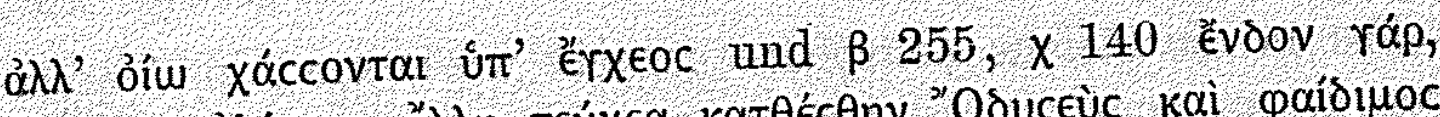

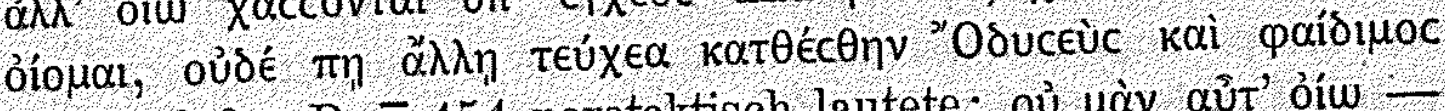

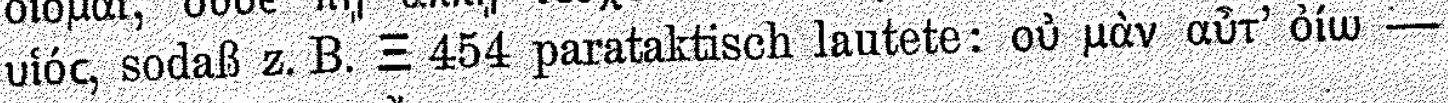

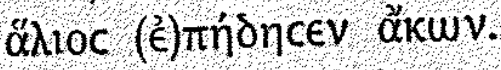

4. Die Aktionsart des futurum läßt sich nieht allgemein feststellen: sie ist teils punktuell, teils durativ. Da die Wurzel meist punktuell ist, so überwiegt die punktuelle Aktion. Es machen sich aber noch Einflüsse anderer Tempora geltend, ron denen aus Futura gebildet werden, des Präsens, des Aorists, des Perfekts, sowie gewisse Analogiewirkungen: vgl. Brugmann Griech. Gramm. 3, 479f. und Delbrück Vergl. Syntax I, 252 ff. Im folgenden ist die Aktionsart einiger der wichtigsten Futura und ihrer Infinitive genauer untersucht.

Das von der W urzel es sein mit durativer Aktion gebildete Futurum zeigt dieselbe Aktion ausschließlich in der 1, und 2. Person Sing. und Plur, wenigstens finde ich kein Beispiel, in dem punktuelle Aktion außer Zweifel stiunde. Dagegen ist in der 3 . Person Sing. daneben punktuelle A ktion in zahlreichen Beispielen nachzuweisen. Ich hebe nur die heraus, die keinen Zweifel

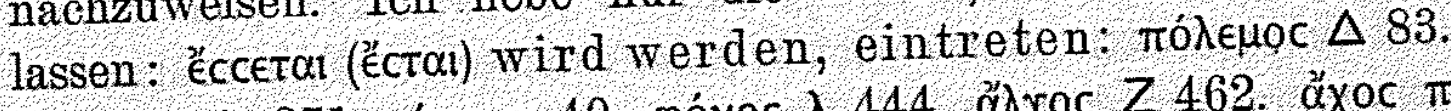

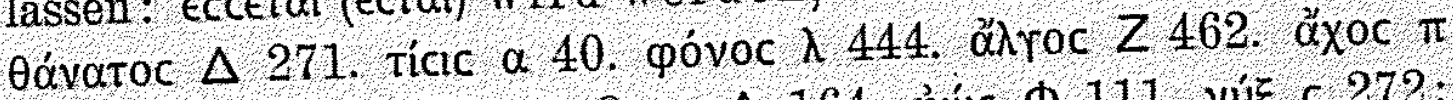

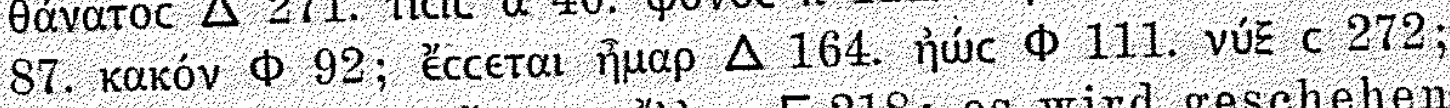

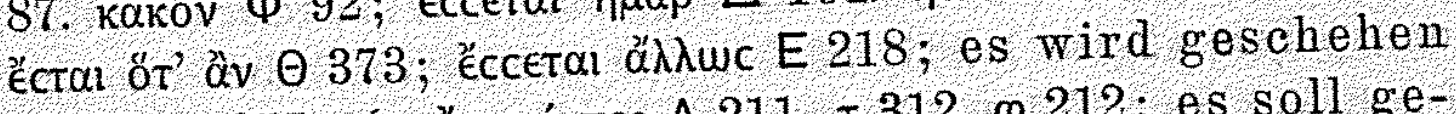

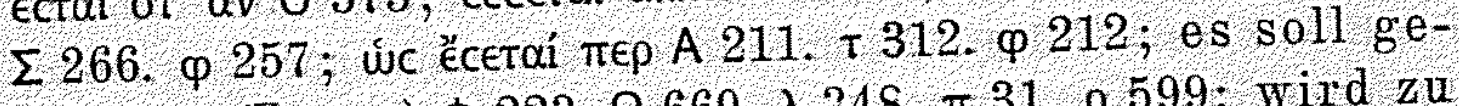
schehen (Zusage) $\Phi 223 . \Omega 669 . \lambda 348 . \pi 31 . \rho 599$; wird zu

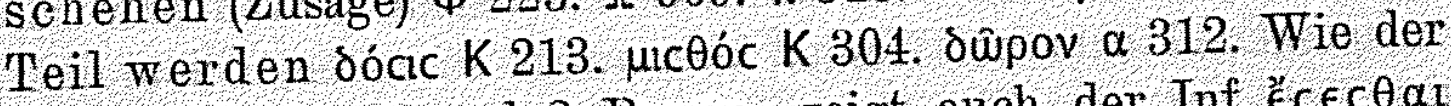
Ind. Fut. in der 1. und 2. Person, zeigt auch der Inf. éc $c \subset c \theta a$ in Bezug auf die 1. und 2. Person durative Aktion: 1. Sing. ท 270. 1. Plur. M 324. 2. Sing. X 332. r 375. o 494, punktuelle vielleicht $E$ 644. In bezug auf die 3 . Person Sing. und Plur. hat écec $\theta$ al teils durative A ktion: $=56.68 .0$ 613. P 278. c 146, teils punktuelle: $Z 339$ (daß es so besser werden wird). $\Lambda 444$.

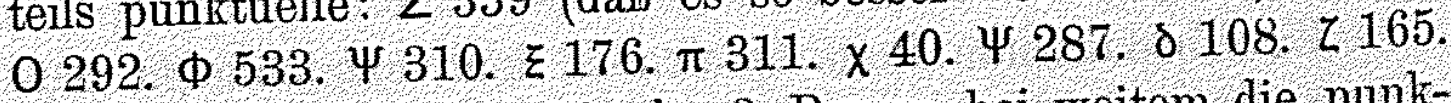
1 230. Es überwiegt also in der 3. Person bei weitem die punktuelle Aktion, die Odyssee bietet (außer c 146 àméccec $\theta \alpha \imath$ ) überhaupt kein Beispiel von durativer Aktion. Offenbar rerwandte die Sprache das Fut. von cíí zum Teil als Ersatz für das von rívouar nicht gebildete Futurum.

Ton den beiden Futurbildungen ' $\varepsilon w$ und $c x n^{\prime} c w$ schließt sich die erstere an das Präsens Ě $\chi \omega$, die letztere an den Aorist 
Écxov an, und dem entsprechend weist Mutzbauer S. 78 jener die Bedeutung 'werde haben, behalten', dieser die Bedeutungen 'werde abbringen von etwas, hintreiben nach' zu (Brugmann Griech. Gramm.3, 480: 'werde anhalten, abbringen'). Indeß läßt sich diese Unterscheidung nicht durchführen. Zwar ist die durative Bedeutung von $\varepsilon^{\xi} \omega$ überall deutlich, nur liegt vielleicht

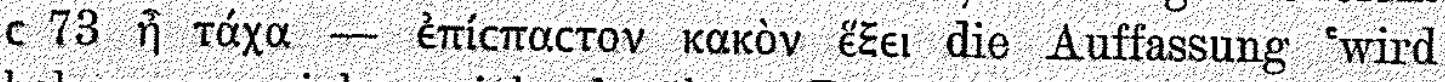
bekommen, sich zuziehen' näher. Dagegen zeigt cxńcw neben der punktuellen Bedeutung ( $P$ 182. $\lambda$ 70. $\times 70.248$ ) ofter die

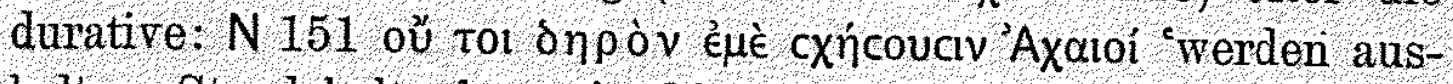

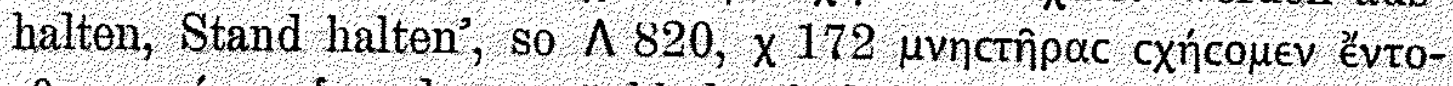
$c \theta \in V \mu \in \gamma \alpha \dot{\rho} \omega \nu v$ 'werden zurückhalten', daß sie nicht herausbrechen können (nicht 'werden zurücktreiben'), $\equiv 100$ oủ ràp 'Axaıoi

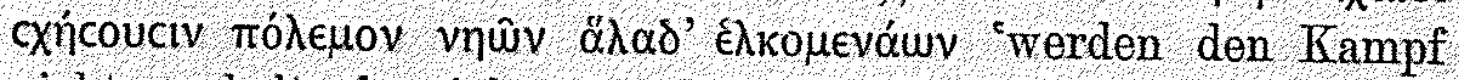
nicht aushalten, nicht: werden ron den Schiffen abbringen

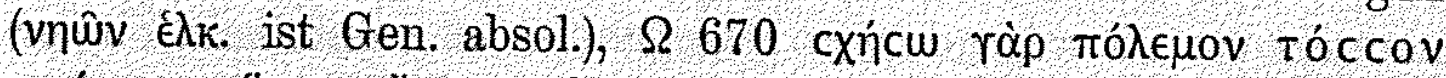

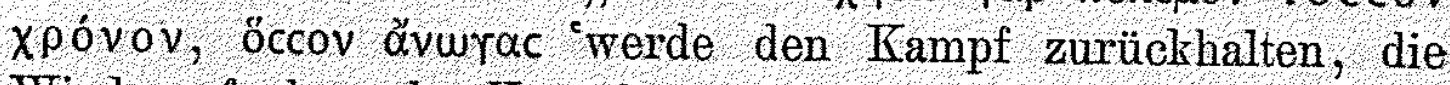

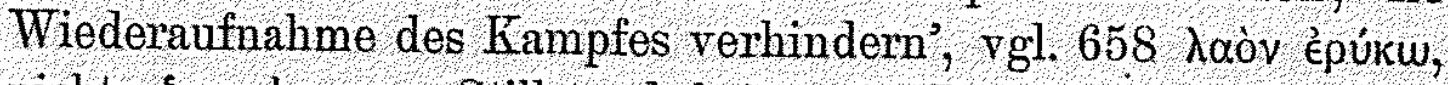
nicht: 'werde zum Stillstand bringen'. Der nur zweimal vorkommende Inf, E Eelv hat E 473 deutlich die durative Bedeutung

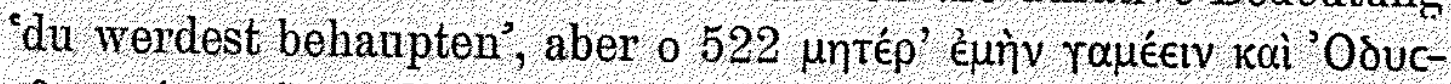

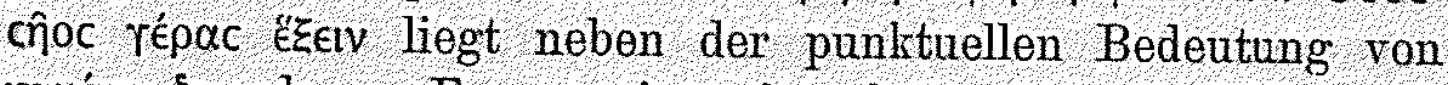
rau'élv 'werde zur Frau gewinnen' auch für éEelv die Bedeutung 'werde erhalten' näher, als 'werde besitzen'. cxíceiv ist M 4, wenn Tpŵac zu ergänzen, 'zurüekhalten', wenn intransitiv gesagt, 'vorhalten', M 166 'aushalten, standhalten'. Das Med. cxn'-

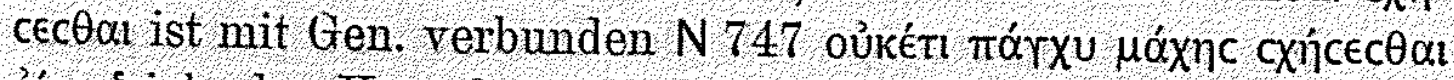
óiw 'sich des Kampfes enthalten, vom Kampfe ruhen werde?, also durativ, dagegen punktuell P 503 'den Ansturm aufgeben' und I 655 'rom Kampf ablassen, den Kampf aufgeben', ohne

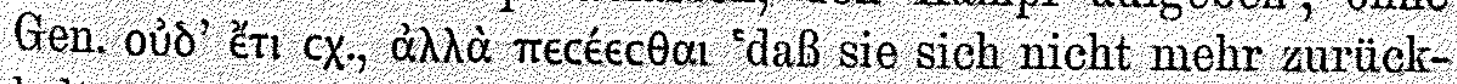
halten, stehenbleiben, sondern einbrechen werden' 1 235. P 639, 'sich halten, standhalten werden' M 107. 126. ávcxńcєec $\theta$ al E 104. 285 ist durativ 'aushalten werden'. Mithin überwiegt bei cxńcw, cxńcelv und exńceceai die durative aktion.

Das Fut. ó $\psi$ o $\mu a \imath$ hat dem Begriff der Wurzel entsprechend die punktuelle Bedeutung ich werde erblicken': $\lambda 450 . \mu$ 101. o 516 (wird dich nicht zu sehen belommen). ค 7. $\Delta 353 . \Psi 620 . \Omega 601$. Wenn aber mit dem Objekt ein die Handlung in ihrem Verlauf bezeichnendes Partiz. Präs. prädikativ verbunden ist, wie $\Theta 475$ 


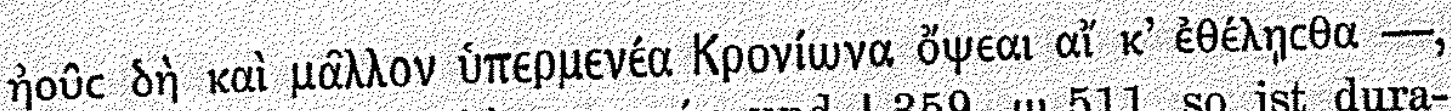

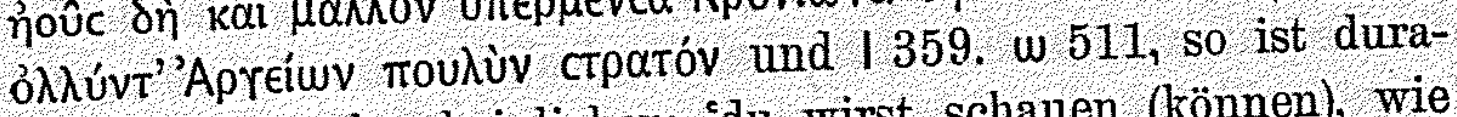
tive Aktion wahrscheinlicher: 'du wirst schauen (können), wie er vernichtet'. O' $\psi \in c \theta \in \Omega \quad \Omega 04$ und $\theta 313$ ist wohl Imperativ des gemischten Aor. : 'schaut'. Der Infin. o' $\psi \in C \theta a l$ hat überall punktuelle Altion 'erblicken werden', durative sicher nur E 120 oủ $\delta$ é

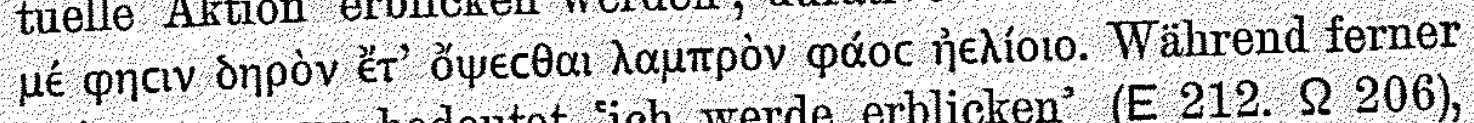
¿có $\psi \circ \mu \alpha \uparrow$ nur bedeutet 'ich werde erblicken' (E 212. $\Omega$ 206), zeigt $€ \pi \imath \circ \psi \circ \mu \alpha \imath$ teils die Bedeutung 'werde ausersehen, auslesen' (I 167. B 294), teils 'werde schauen ( $\equiv 145$. v 233). Die durative Aktion ist dem Einfluß des Präsens ópáw zuzuschreiben.

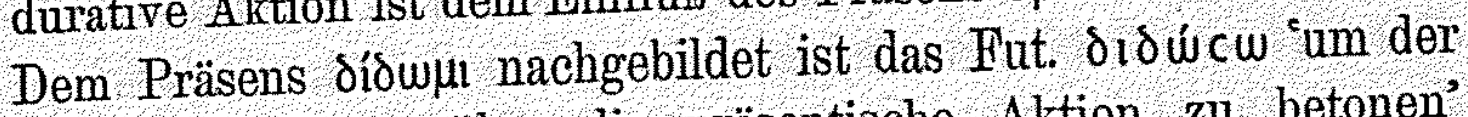
Form oúcu gegenüber die präsentische Aktion zu betonen' (Brugmann Griech. Gramm. 3 S. 481). Auf dieser beruht die

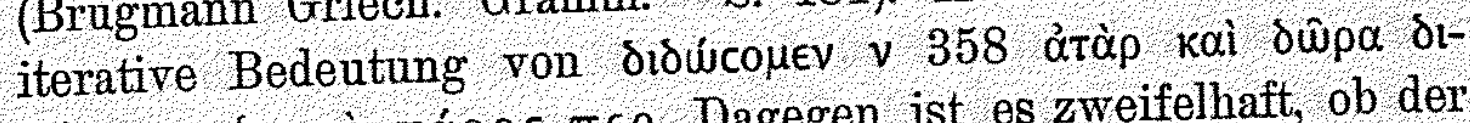

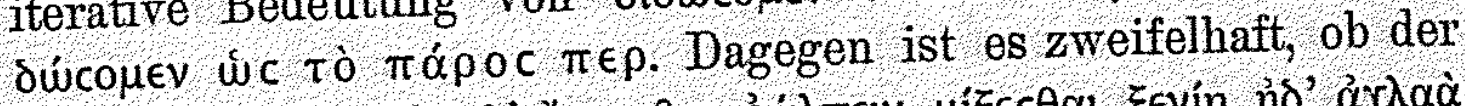

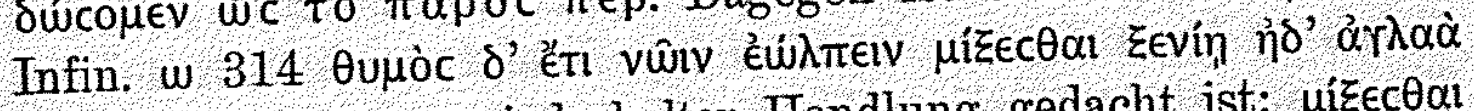

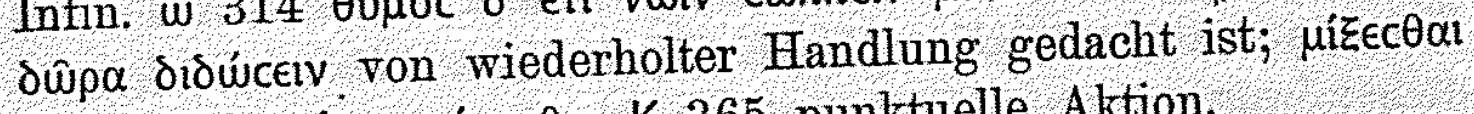

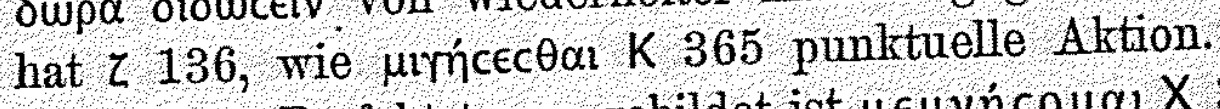

Vom Perfektstamm gebildet ist $\mu \in \mu \nu \eta \dot{c} c o \mu \alpha_{l} X 390$ in perfektisch-durativer Bedeutung ich werde eingedenk bleiben' (im

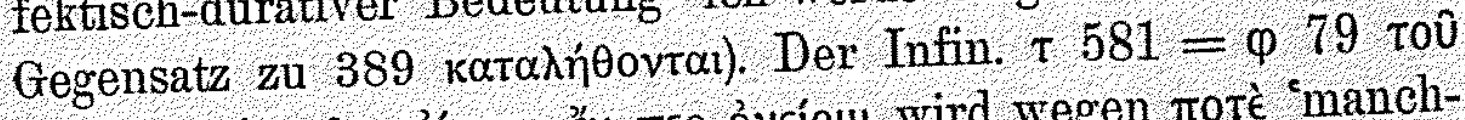

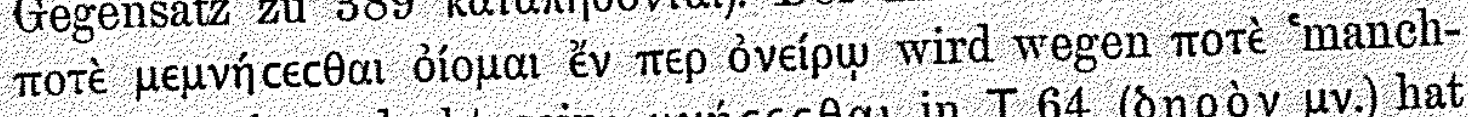

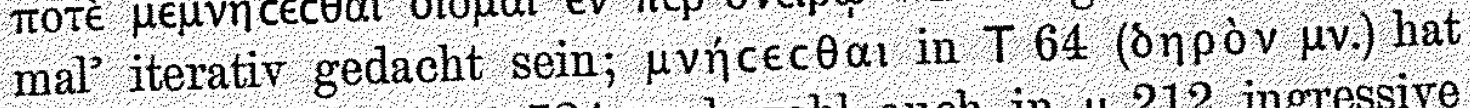
durative Aktion, in $\beta 724$ und wohl auch in $\mu 212$ ingressive Bedeutung, letztere in Übereinstimmung mit $\Delta 172$.

Der Inf. eidńcelv hat, wie der Ind. eiońceic $\eta 327$, punktuelle Altion: kennen lernen, erfahren werde: A 546. 乙 257. Vom Fut. écoudi ist der Inf. nicht gebildet. - Punktuelle A ktion

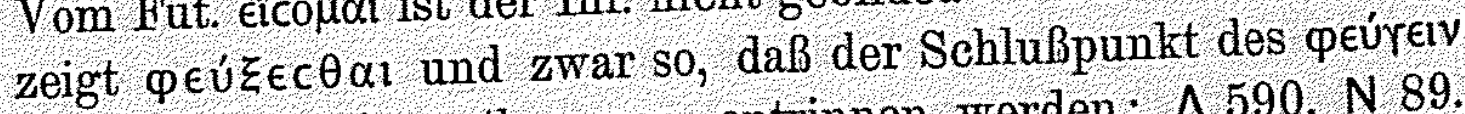
bezeichnet wird: entkommen, entrinnen werden: $\Lambda 590 . N 89$. $0700 . \Phi 93 . \times 67$, während der Ind. Fut. $\Sigma 307$ den Anfangspunkt bezeichnet: ich werde die Flucht ergreifen; in B 159. 175 kann die Aktion verlaufend gedacht sein. Ziemlich selten sind Inf. Fut. von Verben des Affekts und der Affektsäußerung. Von xaípelv 'froh sein' finden sich die Inf. $\chi a 1 p n ̃ c e l v ~ Y 363$ oủ

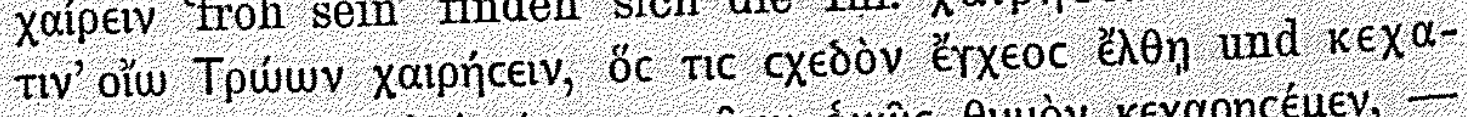

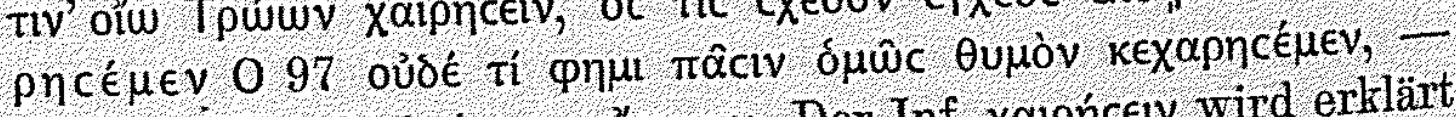

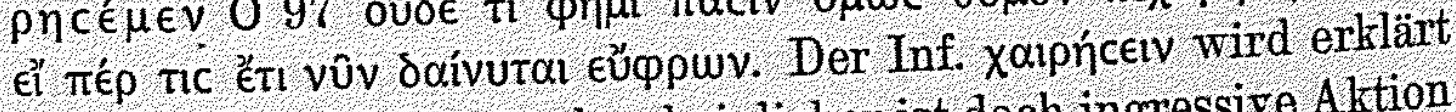
'werde froh sein', aber wahrscheinlicher ist doch ingressire Alktion 
Aktionsart u. Zeitstufe der Infinitive in den homerischen Gedichten. 289

'werde froh werden', negiert in dem Sinne 'es werde ihm übel

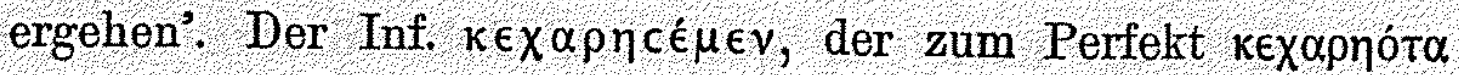
H 312 zu stellen ist, wie $\mu \in \mu v n ́ c o \mu \alpha \iota ~ z u ~ \mu \epsilon ́ \mu v \eta \mu \alpha$, wird durative Altion haben, denn der folgende Nebensatz $\epsilon l$ $\pi \in \rho$ - eủ $\varphi \rho \omega V$ nötigt zu verstehen 'froh bleiben werde'. Dieselbe Bedeutung

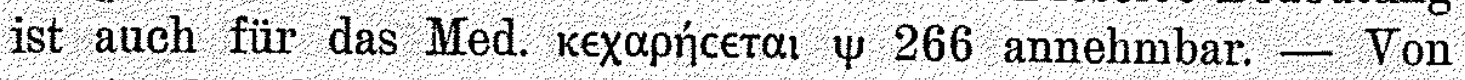

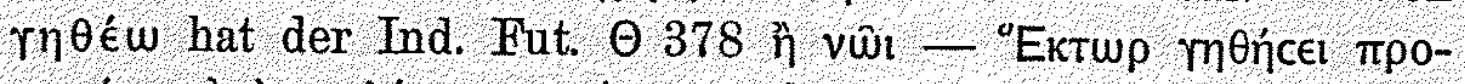

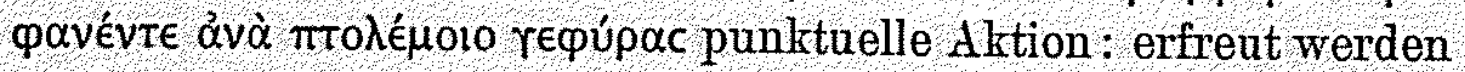

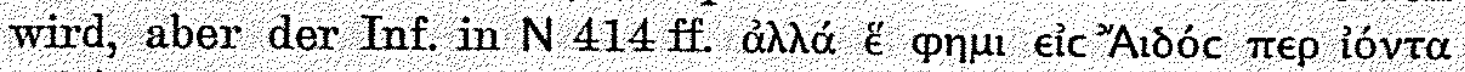

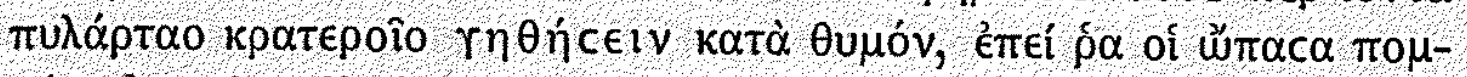
róv durative 'froh sein werde, obwohl er auf dem Wege in das Haus des Hades ist, weil er einen Begleiter hat. $-\delta$ eíow zeigt im Ind. Fut. Y 130 ingressive Bedeutung "wird in Furcht ge-

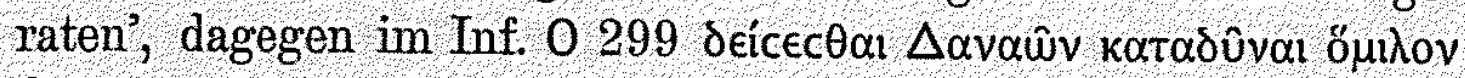
durative 'sich scheuen werde'. - Der Inf. Fut. àrá cceco $\alpha_{1}$ liegt nach Aristarchs Schreibung $\theta 565$ und v 173 (vulg. áróc$c \alpha c \theta \alpha 1)$ vor mit ingressiver Bedeutung 'werde Eifersucht fassen', in $\delta 181$ wird dieselbe Form nach $\mu \epsilon \hat{\lambda} \lambda \in \nu$ als Inf. des gemischten

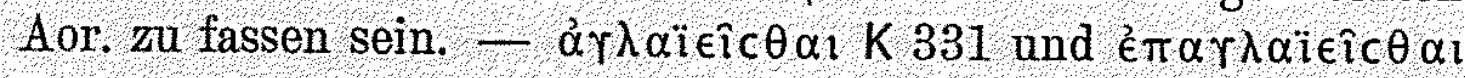
$\Sigma 133$ haben durative Altion. - $\mu \in \tau \alpha \kappa \lambda \alpha u ́ c \in c \theta \alpha_{1} \wedge 764$ steht in Übereinstimmung mit dem Ind. $(\Sigma 340, Y 210, \times 87)$ durativ.

Es ist noch ein Wort zu sagen über die von Verben des Strebens und Wollens abhängigen Inf. Fut. Die Verba sind: $\mu \epsilon-$

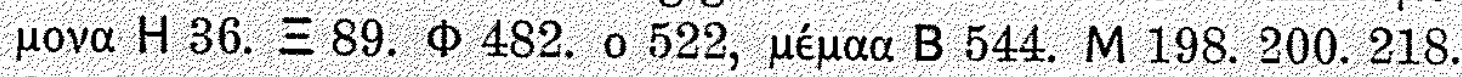

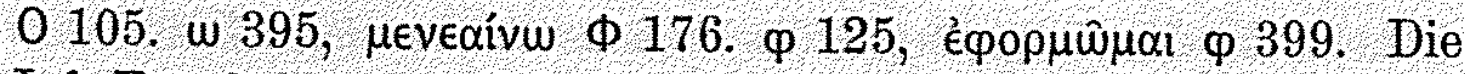
Inf. Fut. haben sämtlich punktuelle Aktion. Dieser den sonst überwiegenden Inf. Präs. und Aor. gegenüber befremdende Gebrauch mag mit Kühner Griech. Gramm. ${ }^{3}$ I, 1,184 und Brugmann Griech. Gramm. 3, S. 497 daraus erklärt werden, daß diese Verba, wenigstens zum Teil, ursprünglich den Sinn des Denkens oder Meinens gehabt haben, wie $\mu \in \mu_{0}$ o 'ich habe den Gedanken gefaßt?, oder nach G. Curtius den Begriff des strebenden Denkens in sich enthielten. Daß der Gebrauch aber als eine Antiquität anzusehen, ist unwahrscheinlich, da die Beispiele den Gesängen der Ilias B (Schiffskatalog) HM=0Ф, also nur jüngeren Gesängen oder jüngeren Partien angehören.

Göttingen.

C. Hentze. 